\title{
Microstructural controls on the pressure-dependent permeability of Whitby Mudstone
}

Rosanne Mckernan ${ }^{1}$, Julian Mecklenburgh*, Ernie Rutter and Kevin Taylor

School of Earth and Environmental Sciences, The University of Manchester, Oxford Road, Manchester, M13 9PL, U.K.

1: Now at Shell International Ltd. 40 Bank Street, London, E14 5NR, UK

*corresponding author: mecklenburgh@manchester.ac.uk

\section{Abstract}

A combination of permeability and ultrasonic velocity measurements allied with image analysis is used to distinguish the primary microstructural controls on effective-pressure dependent permeability. Permeabilities of cylindrical samples of Whitby Mudstone were measured using the oscillating pore pressure method at confining pressures ranging between 30-95 MPa and pore pressures ranging between 1-80 MPa. The permeability-effective pressure relationship is empirically described using a modified effective pressure law in terms of confining pressure, pore pressure and a Klinkenberg effect. Measured permeability ranges between $3 \times 10^{-21} \mathrm{~m}^{2}$ and $2 \times 10^{-19} \mathrm{~m}^{2}$ ( 3 and $200 \mathrm{nd}$ ), and decreases by $\sim 1$ order of magnitude across the applied effective pressure range. Permeability is shown to be less sensitive to changes in pore pressure than changes in confining pressure, yielding permeability effective pressure coefficients $(\chi)$ between 0.42 and 0.97 . Based on a pore-conductivity model which considers the measured changes in acoustic wave velocity and pore volume with pressure, the observed loss of permeability with increasing effective pressure is attributed dominantly to the progressive closure of bedding-parallel, crack-like pores associated with grain boundaries. Despite only constituting a fraction of the total porosity, these pores form an interconnected network that significantly enhances permeability at low effective pressures.

The pre-publication reference is: Mckernan, R., Mecklenburgh, J., Rutter, E. H. and Taylor K.G. (2017) . Microstructural controls on the pressure-dependent permeability of Whitby mudstone. In (E. Rutter, J. Mecklenburgh \& K. Taylor, eds) Geomechanical and Petrophysical Properties of Mudrocks, Geological Society of London Special Publication 454, doi:.org/10.1144/SP454 (In Press). 
Keywords: mudstone, permeability, effective pressure, shale gas

Supplementary Material: A CSV file containing all experimental conditions and a tabulation of results is available at ...

Measuring the fluid-transport properties of rock samples under stress is essential to understanding and predicting the migration of fluids within the subsurface. Mudstones constitute 60-70 \% of the sedimentary rocks within the Earth's crust (Blatt 1992), and an understanding of their physical rock properties is required for many geo-engineering applications including geo-hazard studies (e.g. faults and landslides), basin-evolution studies, hydrocarbon exploration, deposition of landfill, nuclear waste disposal and $\mathrm{CO}_{2}$ storage. Progress in understanding fluid transport properties of mudstones is currently hindered by a scarcity of published experimental data. However, the ongoing expansion of the hydrocarbon industry into low-permeability unconventional resources is driving the demand for research and development in this field. Even when hydraulic fracture treatment is used to enhance production, flow of hydrocarbons into the fractures will be controlled ultimately by the microporous, low permeability matrix. Furthermore, during reservoir production pore-fluid pressure is progressively reduced, which acts to increase the in-situ Terzaghi effective pressure (defined as overburden pressure minus pore pressure), thereby decreasing permeability. The evolution of permeability of the matrix therefore determines the prediction of long-term production, which must take into account the effects of flow regime, multiphase flow, sorption effects, permeability anisotropy and, most importantly, the pressuredependence of permeability.

Laboratory measurements of permeability of intact mudstone samples performed under reservoir conditions has yielded values between $10^{-22} \mathrm{~m}^{2}$ and $10^{-12} \mathrm{~m}^{2}(0.1 \mathrm{nD}$ and $1 \mathrm{D})$ for flow both parallel and normal to layering (Morrow et al. 1984; Katsube et al. 1991; Coyner et al. 1993; Schlömer \& Krooss 1997; Dewhurst et al. 1998; Faulkner \& Rutter 2000; Kwon et al. 2001; Hildenbrand et al. 2004; Kwon et al. 2004; Yang \& Aplin 2007; Metwally \& Sondergeld 2011; Chalmers et al. 2012; Clarkson et al. 2012a; Ghanizadeh et al. 2014a; Ghanizadeh et al. 2014b; Heller et al. 2014; Morrow et al. 2014). Where quantified, the relationship between permeability and effective pressure may be empirically described by either an exponential function (Katsube et al. 1991; Schlömer \& Krooss 1997; Chalmers et 
al. 2012; Ghanizadeh et al. 2014b) or a power law function (Katsube et al. 1991; Kwon et al. 2001; Metwally \& Sondergeld 2011). It has also been demonstrated that for the permeability of clay-bearing rocks, the assumption that effective pressure is simply the difference between confining pressure and pore pressure is not generally valid, as the permeability may be either more or less sensitive to pore pressure than the confining pressure (Kwon et al. 2001; Heller et al. 2014; Letham \& Bustin 2016). For a clay-bearing sandstone, permeability was found to be up to seven times more sensitive to pore pressure than to confining pressure (Zoback \& Byerlee 1975; Walls \& Nur 1979) whereas for a variety of shales, Heller et al. (2014) found permeability to be more sensitive to confining pressure than to pore pressure. For the purpose of modelling production from gas reservoirs it is especially important to take into account effect on permeability of both the pore pressure and the confining pressure, because it is the pore pressure that declines as gas is extracted during production.

This investigation uses direct measurements of permeability, pore compressibility and ultrasonic velocity on intact core plugs to identify the factors controlling the transport of fluid through mudstones at the matrix scale, and to discover how these controls are affected by changes in effective pressure. Within the rock matrix these properties are controlled primarily by pore geometry and connectivity, therefore as pore characteristics alter with changes in lithostatic (confining) pressure and pore fluid pressure, so too will the efficiency of fluid transport. Refining understanding of these fundamental properties of mudstones will improve the accuracy not only of unconventional-reservoir production models, but of any calculations of in-situ stresses, pore fluid pressure variations and burial history within sedimentary basins.

\section{Background}

Permeability, $k_{i j}\left(\mathrm{~m}^{2}\right)$, is a measure of the ease of flow of a fluid of viscosity $\mu$ (Pa s) through a porous medium for an anisotropic material that can be represented as a 3x3 matrix and is empirically described by Darcy’s law (equation 1):

$$
J_{i j}=-\frac{k_{i j}}{\mu} \nabla P
$$

where $J_{i j}\left(\mathrm{~m} \mathrm{~s}^{-1}\right)$ is the matrix of fluid fluxes (volume of fluid crossing an area of $1 \mathrm{~m}^{2}$ per second), and $\nabla P$ is the 3D pressure gradient $\left(\mathrm{Pa} \mathrm{m}^{-1}\right)$. The SI unit of permeability is $\mathrm{m}^{2}$, but in the hydrocarbon industry it is most commonly expressed in Darcys, where $1.0 \mathrm{D}=0.987$ 
$\times 10^{-12} \mathrm{~m}^{2}$. Equation 1 is a differential equation which has to be integrated over pressure to obtain a solution that can be used in any specific situation. For example, a 1 dimensional flow along a sample of length $L$ of compressible gas means that the flow rate is not constant along the flow path because the gas expands as it moves down the pressure gradient. Thus equation 1 becomes:

$$
J=\frac{k}{\mu} \frac{\left(P_{1}^{2}-P_{2}^{2}\right)}{2 L P_{2}}
$$

where $P_{1}$ and $P_{2}$ are the upstream and downstream pressures respectively. Conventional reservoir rocks typically have a permeability on the order of $10^{-13} \mathrm{~m}^{2}(100 \mathrm{mD})$ (Mavko et al. 2009), whereas the permeability of a mudstone commonly lies between $10^{-18}-10^{-21} \mathrm{~m}^{2}(1$ $\mu \mathrm{D}-1 \mathrm{nD})$.

Although Darcy flow is the dominant mechanism of fluid transport within the pores of conventional reservoir rocks, gas transport in mudstones and other tight rocks with sub- $\mu$ mscale pore throats will be affected, at low pore pressures, by gas slippage phenomena that may cause deviations from Darcy's law (e.g. Klinkenberg 1941). The Knudsen number is the ratio of the molecular mean free path length of the gas molecules, $\lambda(\mathrm{m})$, to the characteristic length of the porous medium (in this case the mean pore width). This dimensionless number is indicative of the flow regime occurring in the porous medium. Darcy-type laminar flow occurs when the Knudsen number is small i.e. when gas pressures are high (mean free path small) and pore widths are large. At low gas pressures and small pore widths Knudsen flow becomes dominant and the gas slippage effect occurs due to the increased probability of molecule - pore wall interactions compared to the probability of molecule-molecule interactions. Thus gas molecules flow more easily than under the no-slip condition and apparent permeability calculated using Darcy's formula would become increased. To account for any such gas slippage contribution, Klinkenberg (1941) combined Darcy's law with the Hagen-Poiseuille law for flow through a pipe showing that when slippage does enhance gas flow, the relationship between apparent (measured) permeability $\left(k_{a}\right)$ and 'true' permeability $\left(k_{\infty}\right)$ (i.e. permeability when gas slippage effects are negligible, such as for liquids or flow at high gas pressures) is

$$
k_{a}=k_{\infty}\left(1+\frac{4 m \lambda}{c}\right)
$$


where $m$ is a proportionality constant and $c$ is the capillary radius (m). Because mean free path is inversely proportional to mean pore gas pressure $\left(P_{p}\right)$, equation 3 can be written as

$$
k_{a}=k_{\infty}\left(1+\frac{K_{b}}{P_{p}}\right)
$$

where $K_{b}$ is the slippage factor (or Klinkenberg parameter), reflecting the extent to which permeability is affected by slippage as a function of pore pressure $P_{p}$. When modelling production from gas reservoirs, the flow enhancement through the gas slippage effect can become important during the final stages of production when pressures as low as $1 \mathrm{MPa}$ may be reached (Clarkson et al. 2012b).

\section{Pressure-dependent permeability}

Variations in physical rock properties (e.g. strength, elasticity, acoustic wave velocity and permeability) with applied pressure are usually described as a function of effective stress $\sigma_{i j}^{\text {eff }}$, defined by Terzaghi (1923) as the difference between the total stress $\left(\sigma_{i j}\right)$ and the hydrostatic pore fluid pressure $\left(P_{p} \delta_{i j}\right)$, where $\delta_{i j}$ is the Kronecker delta. Terzaghi's effective pressure law does not account for different sensitivities of the measured property to changes in pore pressure and confining pressure, therefore it is often modified by including a coefficient that adjusts the effectiveness of the pore pressure on the total pressure and was first introduced by Biot (1941) to explain poroelasticity

$$
\sigma_{i j}^{\mathrm{eff}}=\sigma_{i j}-\chi P_{p} \delta_{i j}
$$

The value of the effective-pressure coefficient $\chi$ may be different for different physical properties. Nur \& Byerlee (1971) used the permeability effective pressure coefficient $\chi$ to account for different sensitivities of volumetric strain to pore pressure and confining pressure.

The permeability effective pressure coefficient, $\chi$, has been measured on granite (Coyner 1984; Morrow et al. 1984; Bernabé 1986; Bernabe 1987), sandstone (Zoback \& Byerlee 1975; Walls \& Nur 1979) and mudstone (Kwon et al. 2001; Heller et al. 2014). For granite, $\chi$ tended to 1 with pressure cycling (Bernabé 1988); for clay-bearing sandstones Zoback \& Byerlee (1975) and Walls \& Nur (1979) measured values of $\chi$ between 1 and 7.1. For a variety of mudstones Heller et al. (2014) measured values of $\chi$ between 0.15 and 0.85 , whilst Kwon et al. (2001) measured values of $\chi$ close to 1 . To explain $\chi>1$ it is common to invoke a “clay-pore model” (Zoback \& Byerlee 1975; Seeburger \& Nur 1984; Kwon et al. 
2001; Al-Wardy \& Zimmerman 2004) whereby the pores between a framework of rigid grains are lined by more compliant phases such as clays or kerogens, or partially saturated with liquid. With increased pore pressure, the compliant minerals are compressed and as a result pore diameter (and thus permeability) is increased. Complementary to this, Berryman (1992) showed that theoretically for $\chi$ to exceed unity a rock had to consist of more than one phase with differing compressibilities, while the measurements by Walls \& Nur (1979) showed $\chi$ to increase above 1 with increasing clay fraction in sandstones (Al-Wardy \& Zimmerman 2004). For $\chi<1$ the pore pressure is less effective at opening the pore throats than the confining pressure is at closing them.

\section{Sample preparation and description}

Samples from the Grey Shale member of the Whitby Mudstone Formation were collected from two locations in the intertidal zone on a wave cut platform at Runswick Bay, Yorkshire, UK (UK grid location NZ 815 154), shown in Figure 1. Cores 25 mm in diameter were taken from blocks from both locations in orientations both parallel and perpendicular to bedding, ranging in length between $25 \mathrm{~mm}$ and $35 \mathrm{~mm}$ (Table 1). Length and diameter of each sample was measured to an accuracy of $0.01 \mathrm{~mm}$ and weighed to a precision of $0.001 \mathrm{~g}$, before and after being oven dried at $60{ }^{\circ} \mathrm{C}$ until the mass measured remained constant. At this temperature the structures of organic particles or expandable clays remain unaltered (Bush et al. 1970). After permeability testing, a polished thin section of each sample was prepared perpendicular to the sample axis and analysed for composition and texture using both transmitted light and scanning electron (SEM) microscopes. Optical photomicrographs representing the texture of each sample were processed in ImageJ (Schneider et al. 2012), to determine the silt content. Element maps of compositionally representative areas were measured using energy dispersive X-Ray spectroscopy in the SEM, showing the relative distribution of particular elements present, and from this mineralogy could be inferred. The element maps were processed in ImageJ and layered to create maps showing the mineralogical constitution of each sample (Figure 2d).

\section{Sample description}

The Whitby Mudstone Formation forms part of the Lias group, a thick succession of siliciclastic mudstones deposited in the Cleveland basin during the early Jurassic period (Rawson \& Wright 1995). The high illite content in the Whitby Mudstone (90\% of clay 
grains are illite) suggests a maximum burial depth of $4 \mathrm{~km}$ (Kemp et al. 2005). Textural and mineralogical evidence indicates that a low rate of burial has resulted in mostly early-stage diagenetic reactions going to completion (Pye \& Krinsley 1986).

All samples are silt-bearing, clay-rich mudstones homogenised by bioturbation. Where preserved, mm-scale bedding-parallel lenses in-filled either with clay, silt or pyrite produce a mottled texture (Figures 2a and 2b). These structures are the result of organisms colonizing the sediment (e.g. Chondrites isp., Phycosiphon isp., Rhizocorallium isp. and Planolites isp. (Ghadeer 2011; Ghadeer \& Macquaker 2011). The sample sets from the two locations marked in Figure 1 exhibit subtle differences: Samples from one block (RA1, RA2, RA6 and RC7) comprise homogeneous host sediment containing isolated, silt-filled burrows with high concentrations of pyrite (e.g. Figure 2a). The samples from the other block (RA12, RA13 and RA14) have a more mottled texture as both clay-filled and silt-filled burrows with gradational boundaries are distributed throughout the sample, and burrows show very little (if any) pyritization (e.g. Figure 2b). Where present, relict burrows are set in a background of detrital silt comprising quartz, muscovite/chlorite and feldspar (40\%) with minor carbonate and rutile fragments (1.5\%), which are evenly dispersed throughout an illitic and kaolinitic clay matrix (>55\% area) containing minor amorphous organic matter (1.5\% area) and framboidal pyrite ( $2 \%$ area) (Figures 2c and 2d). Silt grains range in size from $<10 \mu \mathrm{m}$ to $50 \mu \mathrm{m}$ and constitute $40-50 \%$ of the host sediment, and at the sub-mm scale common alignment of the mica, chlorite and clay grains is evident (Figure 2e). Post-compaction diagenetic pyrites (framboidal, with euhedral grains, $1-10 \mu \mathrm{m}$ in size) have precipitated in voids throughout the matrix and are mostly associated with amorphous organic matter (Figure 2f). Diagenetic kaolinite is also present throughout the matrix both as minor patches (1-10 $\mu \mathrm{m}$ in size) and in the form of larger rounded shapes up to $50 \mu \mathrm{m}$ across, either replacing grains or infilling shelter porosity. Following the nomenclature scheme of Macquaker \& Adams (2003), this rock is described as a bioturbated silt-bearing, clay-rich mudstone.

\section{Methods}

\section{Porosity}

Porosities of the core plugs were derived using a Res Lab digital helium pycnometer which measures the grain volume $V_{g}$ of a porous sample using the Boyle's Law method. The 
porosity is then calculated from the bulk volume $V_{b}$ (from calliper measurements) and grain volume of the sample.

$$
\phi=\frac{V_{b}-V_{g}}{V_{b}}
$$

The fine grain size of mudstones means that because their pore networks consist of highly tortuous pathways with narrow pore throats, during the measurement procedure, adequate time was always allowed for helium to penetrate the entire pore volume of the sample. A final pressure reading was only taken once the pressure had stabilised to a constant value. The measured porosity for each sample is given in Table 1.

\section{Permeability}

The permeabilities of seven Whitby Mudstone samples were measured using either the oscillating-pore pressure method (Kranz et al. 1990; Fischer 1992; Bernabé et al. 2006; Song \& Renner 2007) or the transient pulse-decay method developed initially by Brace et al. (1968). The oscillating pore pressure method has the advantage of being relatively insensitive to leakages and temperature fluctuations and for reducing experimental timescales. However, the pulse-decay method is more suitable when (i) permeability is extremely low $\left(<10^{-20} \mathrm{~m}^{2}\right)$ for which impractically long oscillation periods would be required, (ii) when permeability is being measured at low pore pressures $(<10 \mathrm{MPa})$ and the high compressibility of the gas can make it difficult to control a pressure oscillation, or (iii) if there is a capillary entry pressure arising from partial saturation of the pore space with a liquid in which case the measured permeability would be the relative permeability.

\section{Pore pressure oscillation technique}

The oscillation method was first utilised for rocks by Kranz et al. (1990) and Fischer (1992), although it was initially proposed by Turner (1958), and uses a fixed-frequency, sinusoidallyoscillating pore pressure signal applied at one end of the sample. The resultant (downstream) signal maintains the same period as the upstream signal, but is amplitude-attenuated and phase-shifted (Figure 3).

Bernabé et al. (2006) re-analysed the oscillating pore pressure method and defined two independent dimensionless material parameters; $\eta$ (dimensionless permeability) and $\xi$ (dimensionless storativity ratio) which are functions of permeability $\left(k \mathrm{~m}^{2}\right)$ and specimen storativity $\left(\beta \mathrm{Pa}^{-1}\right)$ respectively and are defined: 


$$
\begin{gathered}
\eta=\frac{S T k}{\pi L \mu \beta_{D}} \\
\xi=\frac{S L \beta}{\beta_{D}}
\end{gathered}
$$

where $S$ is the sample cross-sectional area $\left(\mathrm{m}^{2}\right), T$ is the oscillation period (s), $L$ the sample length (m), $\beta$ the sample storativity $\left(\mathrm{Pa}^{-1}\right), \beta_{D}$ the downstream reservoir storage $\left(\mathrm{m}^{3} \mathrm{~Pa}^{-1}\right), k$ the sample permeability ( $\mathrm{m}^{2}$ ) and $\mu$ the fluid viscosity (Pa s). Bernabé et al. (2006) improved upon the solutions presented by Kranz et al. (1990) and Fischer (1992) by defining $\xi$ and $\eta$ such that each would be dependent on only one material parameter of the rock, thus allowing them to be assessed as independent material properties. In terms of $\xi$ and $\eta$ the solution to the diffusion equation is

$$
A e^{-i \theta}=\left(\frac{1+i}{\sqrt{\xi \eta}} \sinh \left[(1+i) \sqrt{\frac{\xi}{\eta}}\right]+\cosh \left[(1+i) \sqrt{\frac{\xi}{\eta}}\right]\right)^{-1}
$$

Solving equation 7 to find $A$ and $\theta$ using a range of valid values of $\eta$ and $\xi$ defines the region in which physically meaningful values of $A$ and $\theta$ can be found (Figure 4). The region is limited by the lines $\xi=0$ and $\xi \rightarrow \infty$, therefore any $(A, \theta)$ points that fall outside are, in principle, not possible (Bernabé et al. 2006). Sample storativity $(\beta)$ is directly proportional to porosity $(\phi)$ and is given by

$$
\beta=\phi\left(C_{f}+C_{p}\right)
$$

where $C_{f}$ is the pore fluid compressibility and $C_{p}$ is the compressibility of the porosity in response to changes in pore pressure at constant confining pressure. As $C_{f} \gg C_{p}$ the $C_{f} \phi$ term will dominate. Thus iso- $\xi$ paths are nominally lines of constant porosity for a given value of downstream storage volume provided the compressibility of the pore fluid and the pores remain constant, there are no adsorption-desorption effects and the sample behaves isotropically.

Permeability data for sample RA14 are plotted in Figure 4, showing that as permeability (proportional to $\eta$ ) decreases with increasing confining pressure, the data points migrate 
downwards along a path of near-constant $\xi$. Maintaining a constant $\xi$ track implies no substantial change in porosity over the range of effective pressures used. The permeability is found by solving equation 7 iteratively for both $\eta$ and $\xi$. This was done using a numerical equation solver. Initial values of $\xi$ and $\eta$ were obtained from a look-up table containing the values plotted in Figure 4. The algorithm then sought the values of $\xi$ and $\eta$ that simultaneously solve the modulus and argument of equation 7 which are equal to amplitude ratio $A$ and phase shift $\theta$ respectively:

$$
\begin{gathered}
A=\left|\left(\frac{1+i}{\sqrt{\xi \eta}} \sinh \left[(1+i) \sqrt{\frac{\xi}{\eta}}\right]+\cosh \left[(1+i) \sqrt{\frac{\xi}{\eta}}\right]\right)^{-1}\right| \\
\theta=\arg \left[\left(\frac{1+i}{\sqrt{\xi \eta}} \sinh \left[(1+i) \sqrt{\frac{\xi}{\eta}}\right]+\cosh \left[(1+i) \sqrt{\frac{\xi}{\eta}}\right]\right)^{-1}\right]
\end{gathered}
$$

The sample storativity calculated using $\xi$ from the oscillation technique may be lower than the total storativity of the sample, calculated from porosity $(\phi)$ and the known compressibility of the pore fluid using equation 8 (Fischer 1992). This is because the storativity measured by the oscillating pore pressure technique will only include the part of the porosity accessed in the transport of gas. This is demonstrated for sample RA14 where the storativity $(\beta)$ was calculated from equation 8 for sample RA14 using the measured helium porosity and assuming the compressibility of the pores $\left(C_{p}\right)$ to be negligible. This value differs significantly from storativity obtained from the analysis of the pore-pressure oscillations (Figure 4), implying that the total pore volume measured using the helium pycnometer is not the same as the volume of pores that contribute to the permeability, i.e. the fluid being transmitted through the rock sample during an experiment does not necessarily access the total pore volume.

\section{Pulse-decay technique}

The transient pulse-decay technique involves imposing an instantaneous pore pressure change at one end of a sample. The pulse is dissipated by propagation of pore fluid along the sample length. The differential pressure $(\Delta P)$ between upstream and downstream reservoirs 
gradually diminishes to zero at a rate dependent on permeability (k). Brace et al. (1968) demonstrated, by analogy with a resistor-capacitor filter circuit, that the differential porepressure $\Delta P_{p}$ will decay exponentially with time $(t)$ according to

$$
\Delta P_{p}(t)=\Delta P_{u} \exp (-\omega t)
$$

where $t$ is time, $\Delta P_{u}$ is the magnitude of the initial upstream pressure pulse and $\omega$ is a constant related to permeability $(k)$ by

$$
\omega=\left(\frac{k S}{\mu C_{f} L}\right)\left(\frac{1}{V_{u}}+\frac{1}{V_{d}}\right)
$$

Equation 12 relies on the assumption that sample porosity $\phi$ is small enough to exert a negligible influence on the pressure transient. While this may be valid for crystalline rocks with porosity $<0.01$, pore volumes of sedimentary rocks may in fact compare to downstream reservoir volumes. Following the method of Cui et al. (2009), the relative pore and reservoir volumes can be taken into account by introducing a factor $f_{1}=\vartheta_{1}^{2} /(p+q)$ where $p$ and $q$ (Dicker \& Smits 1988) are:

$$
p=\frac{V_{p}}{V_{u}} \quad \text { and } \quad q=\frac{V_{p}}{V_{d}}
$$

and $f_{1}$ depends on the first solution $\vartheta_{1}$ of the transcendental equation:

$$
\tan \vartheta=\frac{(p+q) \vartheta}{\vartheta^{2}-p q}
$$

The permeability can then be calculated using:

$$
k=\frac{\omega \mu C_{f} L}{f_{1} S \frac{1}{V_{d}}} .
$$

Permeability values determined by oscillating pore pressure and the pulse decay method exhibit good agreement (Figure 5). Permeability was calculated from the pulse transient data using both the solution in Brace et al. (1968) which assumes zero porosity, as well as the solution of Cui et al. (2009) which accounts for the pore volume of the sample measured using helium pycnometry. Permeability of samples RA2 and RA13 calculated using equation 15 (Cui et al. 2009) is slightly higher than that calculated using equation 12 (Brace et al. 1968), and that permeability calculated using equation 12 is closer to permeability measured using the oscillating pore pressure method. This is most likely because, as previously 
mentioned, the pore volume of the sample contributing to storativity $(\beta)$ that is measured during the oscillating pore pressure method is significantly lower than the pore volume measured using helium pycnometry. As a result, permeability calculated using equation 15 with helium porosity will overestimate permeability. For comparison, porosity was calculated from the dimensionless storativity $(\xi)$ measured with the pore pressure oscillation technique, using equation 6. Black crosses in Figure 5 show permeability calculated using equation 15 with porosity set as that calculated from dimensionless storativity $(\xi)$.

\section{Experimental setup}

For all permeability measurements, $25 \mathrm{~mm}$ diameter samples were connected at each end to an upstream and a downstream reservoir with sintered stainless steel porous discs used to ensure uniform pore fluid pressure distribution at each end of the sample. In case weakmineral smearing (carbon or clays, Rutter et al. 2013) had occurred during the end-squaring process, radial scratches were also made at each end of the sample to ensure pore fluid could enter the pore space in the rock. Samples were jacketed in heat-shrink tubing and the assembly was placed into a pressure vessel capable of maintaining pressures up to $400 \mathrm{MPa}$ (Figure 6). The sample assembly was hydrostatically loaded by pressurizing a synthetic oil using a compressed-air driven pump, and the confining pressure was measured using a Honeywell $400 \mathrm{MPa}$ pressure transducer accurate to within 0.5 MPa. Measurements were all made at a controlled ambient temperature of $21^{\circ} \mathrm{C}$ and with each pressure change, time was allowed for adiabatic heating or cooling effects to subside before measurements were taken.

The pore fluid used in all experiments was argon, at pore pressures ranging between $1 \mathrm{MPa}$ and $70 \mathrm{MPa}$. Over most of this pore pressure range, the effect of changes in gas adsorption on the measured permeability is expected to be negligible because firstly, the Whitby Mudstone samples contain very little organic carbon and second, mineral or organic particle surfaces that may adsorb gas will be fully saturated at pore pressures greater than $\sim 16 \mathrm{MPa}$ (Zhang et al. 2012). Viscosity of argon was calculated for a given pore pressure and temperature using the formulation given in Younglove \& Hanley (1986). The compressibility of argon was calculated for a given temperature and pore pressure from the compressibility factor $z$ calculated from fits from equation of state data of Gosman et al. (1969). The behaviour of the gas is almost ideal up to $25 \mathrm{MPa}$, beyond which the compressibility progressively decreases. The upstream and downstream pore pressures were measured using separate HBM $500 \mathrm{MPa}$ pressure transducers with a resolution of $0.01 \mathrm{MPa}$, and the upstream pore pressure was controlled using a volumometer driven by a servo- 
controlled motor (Figure 6). To achieve the highest data resolution possible, the volumes of both upstream and downstream reservoirs were kept to a minimum and the plumbing was insulated to minimise temperature fluctuations. The volumes of the upstream and downstream reservoirs were determined under the conditions of a typical experiment with a steel plug in place of the sample. The upstream volume was determined by measuring the piston displacement needed to impose a small pore pressure change, from which the volume can be calculated using Boyle's law. The downstream volume was calculated by measuring the volume required to keep the pressure constant when opening the downstream volume at zero pressure to the upstream, giving downstream volumes of $721 \pm 13 \mathrm{~mm}^{3}$ and an upstream volume (excluding the volumometer) of $4249 \pm 13 \mathrm{~mm}^{3}$. During pore pressure oscillation experiments the downstream volume was either enlarged (for high permeability samples) or reduced (for low permeability samples) to optimise the downstream signal for processing. The downstream volume used for each test is given in the supplementary data.

\section{Experimental procedure}

During initial pressurization, pore pressure $\left(P_{p}\right)$ and confining pressure $\left(P_{c}\right)$ were always raised in increments to avoid effective pressure $\left(P_{e f f}\right)$ rising above the desired initial value (usually $10 \mathrm{MPa}$ ). Sample permeability was measured under total confining pressures ranging between 35-95 $\mathrm{MPa}$, at pore pressures between 0.7 - $80 \mathrm{MPa}$. After each pressure step the pore pressure volumometer was monitored until it reached a stable value, implying that the sample had equilibrated to the change in the pressure conditions.

To perform a pore pressure oscillation experiment, the upstream and downstream reservoirs were isolated from each other apart from through the sample, and a sinusoidal pore pressure wave was applied to the upstream end. The downstream pore pressure oscillations settle gradually to a steady amplitude and phase shift (Figure 3). Cycle periods were ranged from 100 to 10000 seconds and driving wave amplitudes ranged from 0.5 to $1.5 \mathrm{MPa}$ - always less than $10 \%$ of the background (average) pore pressure. Once the downstream signal provided a detectable response (we find that gains between 0.01 and 0.3 give the best results) and steady state was reached, the experiment was run for a minimum of 10 to 20 cycles. These cycles were then processed using the FFT algorithm in MATLAB® (Matlab 2013) to extract the amplitude and phase of the upstream and downstream signals from which amplitude ratio ( $A$ ) and phase-lag $(\theta)$ were calculated. Equation 7 was then solved to find dimensionless 
parameters $\eta$ and $\xi$ from which permeability and storativity were calculated using equations 5 and 6.

To perform a transient pulse-decay experiment, time was initially allowed for pore pressure to equilibrate across the sample. At time $t_{0}$, upstream pore pressure $P_{u}$ was increased by a small amount ( $<5-10 \%$ pore pressure) in order not to incur much change to the viscosity and compressibility of the fluid and to the value of the effective pressure. During the experiment the upstream pore pressure was held at a constant value using the servo-controlled volumometer, thereby creating an apparently infinite upstream volume (Zoback \& Byerlee 1975). Maintaining a constant upstream pressure both eliminates the possibility of a leak or other sources of pressure variation in the upstream reservoir affecting the results, whilst eliminating the upstream volume from the permeability calculation. The pore pressures were recorded until the downstream pore pressure equalled the upstream pore pressure. The difference between the constant upstream and time-varying downstream pore pressure $(\Delta P)$ versus time was fitted to equation 11 to obtain the gradient $\omega$, which was then used to calculate permeability $k$ using equations 12 and 15.

\section{Uncertainty}

Measurement uncertainties in permeability were determined by propagation of errors (Bevington \& Robinson 1992), using the standard deviation in repeated measurements of variables. Standard deviations of measured variables include $0.059 \mathrm{~mm}$ in length measurements, 0.009 $\mathrm{MPa}$ in pore pressure measurements and $13.52 \mathrm{~mm}^{3}$ in downstream volume. The fractional error in dimensionless permeability $\eta$ was calculated using the technique described by Bernabé et al. (2006) and is generally very low $(<0.04)$, increasing where amplitude ratios lie below 0.01 or above 0.65 . This leads to a fractional error in permeability of $\sim 0.03$ when amplitude ratios are within an optimal range between 0.65 and 0.01 .

Uncertainty in permeability determined using the pulse decay technique was also estimated using propagation of errors. Using the standard deviation of the error in the fit of $\Delta P$ over time $t$ to equation 11 (less than 1\%) along with standard deviations in measured variables, permeability can be determined with an error of \pm 1 to $3 \%$. Any remaining variabilities are attributed to rock sample characteristics, such as hysteresis arising from pressure cycling. 


\section{Pore compressibility}

Pore compressibilities of two samples were determined from measurements of pore volume changes with confining pressure. To detect pore volume changes, the upstream pore pressure control system was set to maintain constant pressure. Changes in pore volume due to externally applied changes in confining pressure were then compensated by movement of the volumometer piston as gas was expelled from or drawn into the pore spaces. Piston displacement was measured until gas flow ceased using a linear variable differential transformer (LVDT) and used to calculate volume displacement to within $\pm 0.7 \mathrm{~mm}^{3}$ accuracy during confining pressure steps. The response in terms of gas flow to each increment in effective pressure is slow owing to the low porosity and permeability of the rock and the small pressure increments induced, therefore the precision of such measurements can be poor for mudstones. Volume change ( $\Delta V)$ due to change in effective pressure $(\Delta P$ ) is given by $\Delta V=C_{\mathrm{p}} \Delta P V_{\mathrm{p}}$, where $C_{\mathrm{p}}$ is pore compressibility and $V_{\mathrm{p}}$ is original pore volume (Walsh 1965b; Zimmerman et al. 1986). Between steps of loading and unloading samples for permeability measurements, pore volume strain was recorded and plotted against pressure. Pore compressibility was obtained from the gradient of a fit to the pressure-volumetric strain data.

\section{Acoustic Wave Velocities}

Ultrasonic P-wave velocities were measured as a function of confining pressure on two Whitby Mudstone samples using the method described by Birch (1960). One specimen was oriented for wave propagation parallel to layering (RA17) and the other normal to layering (RC8). Both samples were cut into cylindrical cores $25 \mathrm{~mm}$ in diameter and $35 \mathrm{~mm}$ in length and dried in an oven at $60^{\circ} \mathrm{C}$. To improve coupling between sample and transducers, a minimal amount of ultrasonic gel was applied between the sample and the pistons. The same samples were then jacketed in heat-shrink tubing for high pressure measurements without pore pressure at room temperature. Velocity measurements were taken at atmospheric pressure and after increments of $<3 \mathrm{MPa}$ confining pressure during three cycles of loading and unloading from 0.7 MPa to $103 \mathrm{MPa}$.

Experimental uncertainty in measured velocities was estimated by error propagation using the standard deviations of multiple length measurements $(0.059 \mathrm{~mm})$ and multiple arrivals of a transmitted signal at the same pressure conditions (14.17 ns), giving a standard deviation of 
$\pm 0.25 \%$. Corrections for both the time-of-flight in the specimen end pieces and the change in length of both the sample and the parts of the apparatus between the acoustic transducers with applied confining pressure were made during the velocity calculation.

\section{Results}

\section{Permeability}

All seven samples were subjected to the same initial pressure cycling routine, whereby confining pressure was increased and decreased (cycled) over the full confining pressure range until variation of permeability with effective pressure was reproducible (Figures 7 and 8 and supplementary data file). All samples exhibited the same permeability-effective pressure behaviour at a constant value of pore pressure, whereby increasing effective pressure for the first time causes a non-recoverable reduction in permeability of up to two orders of magnitude, after which the permeability-effective pressure relationship settles to a reproducible pattern (Figure 7 and 8). The permanence of this observed initial permeability reduction was tested by completely depressurizing one sample after it had been pressure cycled. The depressurization did not fully restore permeability to its original value, implying that permanent physical changes occurred during the initial stage of pressure cycling. All the permeability data for the seven samples range between $3 \times 10^{-21} \mathrm{~m}^{2}$ and $2 \times 10^{-19} \mathrm{~m}^{2}$ (3 and 188 nd).

\section{Pressure cycling}

The effect of pressure history on permeability was investigated by cycling sample RA14 over three different pressure ranges (Figure 8). A large and permanent loss of permeability was observed with each increase in the maximum effective pressure applied, suggesting that the extent of permanent permeability loss is dependent on pressure history. The constant gradients of the log permeability versus effective pressure for each increment of applied maximum effective pressure suggest the elastic sensitivity of permeability to effective pressure is independent of maximum applied pressure (Figure 8). For each pressure range, the sensitivity of permeability to changes in effective pressure brought about by changing pore pressure at constant confining pressure was approximately the same as when the same effective pressure change was brought about by changing the confining pressure at constant pore pressure (Figure 8 and supplementary data file). All samples also exhibit an incremental 
loss of permeability of $<1 \%$ with each subsequent pressure cycle. This effect is most prominent in samples RA6 (plotted in Figure 7) and RA1.

\section{Permeability anisotropy}

Permeability of Whitby Mudstone normal to layering was measured and is substantially lower than permeability parallel to layering (Figure 7). Samples oriented parallel to layering showed a much greater permanent loss of permeability with the initial pressure cycle, decreasing by up to 2.5 orders of magnitude compared to a decrease of one order of magnitude for the sample oriented normal to layering. Permeability anisotropy is commonly defined as the ratio of permeability parallel to layering, to permeability perpendicular to layering. For the Whitby Mudstone this corresponds to a permeability anisotropy factor of $\sim 60$.

\section{Dependence of permeability on effective pressure}

The sensitivity of permeability to Terzaghi effective confining pressure was measured on all seven samples at a constant pore pressure of $25 \mathrm{MPa}$. The data define the permeabilityeffective pressure relationship, fitted here to an exponential law of the form

$$
k=k_{0} \exp \left(\gamma P_{\text {eff }}\right)
$$

where $k_{0}$ is the permeability at zero effective pressure $\left(P_{\text {eff }}\right)$ and $\gamma$ is a coefficient. All seven samples show values of $\gamma \approx-0.03 \mathrm{MPa}^{-1}$, with the exception of sample RA12 which showed a considerably lower sensitivity of permeability to effective pressure $\left(\gamma \approx-0.009 \mathrm{MPa}^{-1}\right.$ see Table 2). Whilst a simple description of the permeability-effective pressure relationship, either an exponential function (equation 16) or a power-law of the form

$$
k=k_{0}\left(1-\frac{P_{\mathrm{eff}}}{F}\right)^{n}
$$

(where $n$ and $F$ are constants), is desirable for application to geological fluid flow models, an exponential function is more commonly used to fit experimental data (Kwon et al. 2001; Bustin et al. 2008; Cui et al. 2009; Heller et al. 2014). This is despite most theoretical relationships between permeability and effective pressure being power-laws (e.g. Shi \& Durucan 2016). Shi \& Durucan (2016) show that the difference between exponential functions such as equation 16 and power-laws such as equation 17 is very small over the range of effective pressures used in experimental studies, and they provide a set of transformation equations from exponential fit parameters to parameters for the models of Gangi (1978). Although permeability at zero effective pressure cannot be measured reliably 
in the laboratory, it can be achieved in the subsurface (e.g. in the orientation of the minimum horizontal stress, $\sigma_{\mathrm{Hmin}}$ ) when pore fluid pressure approaches $\sigma_{\mathrm{Hmin}}$. Despite the fact that, for example, sample RA6 (Figure 7) would be better described by a power-law fit, the quality of the fits to both exponential and power-law functions for the dataset overall shows little difference.

The sensitivity of permeability to pore pressure at constant confining pressure was measured on three samples (Figure 8). During the second and third cycles, pore pressure changes were repeated, showing that the sensitivity of permeability to pore pressure is reproducible. Using multiple linear regression analysis of the change in the natural logarithm of permeability with both confining pressure and pore pressure to find the effective pressure coefficient $\chi$ and the overall pressure coefficient $\gamma$, the data for each pressure range were fitted to a modified effective pressure law (Figure 9) of the form

$$
k=k_{0} \exp \left(\gamma\left[P_{c}-\chi P_{p}\right]\right)
$$

When permeability is more sensitive to changes in pore pressure than changes in confining pressure $\chi>1$, and conversely when it is less sensitive to pore pressure than confining pressure $\chi<1$. Values of $\chi$ obtained in this study are all less than 1 (Table 2).

\section{The Klinkenberg effect}

Permeability was measured over a range of confining pressures between 35 and $95 \mathrm{MPa}$, and pore pressures between 0.5 and $60 \mathrm{MPa}$. Data with pore pressures ( $>25 \mathrm{MPa}$ ) were then fitted to equation 18. All the data were then normalised by the results of this fit and are shown in Figure 10, revealing a notable deviation away from the fit for pore pressures $<10 \mathrm{MPa}$. Permeability becomes enhanced at low pore pressures and this is attributed to the Klinkenberg effect. Figure 10 illustrates the magnitude of deviations from the high pore pressure permeability trend, described by a Klinkenberg parameter $K_{b}$ (equation 4) of $\sim 2$ MPa. The curve $k=k_{0}\left[1+\left(K_{b} / P_{p}\right)\right]$ is plotted in Figure 10 , which clearly shows that gas slippage effects are restricted to pore pressures lower than $10 \mathrm{MPa}$ and therefore do not affect the results of the present experiments that were carried out at higher gas pressures. To describe fully the dependence of permeability on effective pressure, an additional term was therefore applied to equation 18 to account for slip at low pore pressures:

$$
k=k_{0} \exp \left(\gamma\left[P_{c}-\chi P_{p}\right]\right)\left(1+\frac{K_{b}}{P_{p}}\right)
$$




\section{Acoustic wave velocities}

Ultrasonic P-wave velocities parallel and perpendicular to layering were measured at different confining pressures, during three separate pressure cycles up to $100 \mathrm{MPa}$ (Figure 11a). During initial pressurization there is a rapid, nonlinear rise in velocity up to confining pressure of $20 \mathrm{MPa}$, followed by a slower, nearly linear rise across the remainder of the pressure range. The low pressure nonlinearity is most pronounced for wave propagation normal to layering. With unloading, $V_{p}$ perpendicular to layering follows a similar pattern to the loading curve, but displays velocity hysteresis, with velocity decreasing more slowly with pressure in successive cycles. In the second pressure cycle, with wave propagation direction normal to layering, the up-pressure curve exhibited a $4.5 \%$ increase in velocity. However, the unloading curve remained unchanged. This behaviour was also observed by Burke \& Fountain (1990) in samples of marble.

In the third loading cycle on the shale, velocity decreased slightly compared to the second cycle but remained higher than that of the first cycle, suggesting a permanent increase in velocity had taken place during the first loading cycle. There is a clear anisotropy between measurements parallel and perpendicular to layering, consistent with the rock being transversely isotropic with the symmetry axis perpendicular to the layering as is seen in many shales and other foliated rocks (Sayers 2005). The compressional wave velocity parallel to the layering is $29 \%$ faster than perpendicular to the layering at $100 \mathrm{MPa}$ confining pressure. The velocity that is asymptotically approached at high pressure is given in Table 3 and the associated components of the Voigt stiffness matrix have been calculated from these velocities. These are compared to elastic moduli calculated using a Voigt-Reuss-Hill (VRH) average of the all the concentrations of all minerals in the rock and assuming no crystallographic preferred orientation, shown in Table 4. Also shown in Table 4 are the elastic properties of a rock with a solid component with the same elastic properties as those calculated from the VRH average with $6 \%$ porosity, with both spherical pores and oblate ellipsoids with different aspect ratios using a self-consistent approach proposed by Berryman (1995) as set out in Mavko et al. (2009).

\section{Crack porosity and aspect-ratio distribution}

Changes in elastic moduli with pressure (calculated from ultrasonic data) can be used to infer the crack porosity $\phi_{c}$ and aspect ratio distribution $\psi(\alpha)$ of the network of cracks in the rock that close progressively over the applied pressure range. According to Walsh (1965a), large 
initial changes in elastic moduli with pressure are mostly due to progressive closure of microcracks - a process which increases rock stiffness much more than the effect on rock density. These changes in elastic moduli with pressure result in a non-linearity in the stressstrain curve for a particular loading geometry which can be modelled by assuming two or three-dimensional elliptical voids distributed throughout an infinite, solid rock (Jaeger et al. 2009). The hydrostatic pressure required to close an elliptical crack depends upon the elastic properties of the solid matrix and the initial aspect ratio of the crack, $\alpha_{0}$. For a threedimensional penny-shaped crack in an isotropic medium, the closing pressure $P_{\text {close }}$ is related to initial aspect ratio $\alpha_{0}$, the Poisson's ratio $\left(v_{\mathrm{m}}\right)$ and the Young's modulus $\left(E_{\mathrm{m}}\right)$ of the solid matrix by

$$
P_{\text {close }}=\frac{E_{\mathrm{m}} \pi \alpha_{0}}{4\left(1-v_{\mathrm{m}}^{2}\right)}
$$

(Jaeger et al. 2009). Closure pressure increases with increasing aspect ratio, hence longer, thinner cracks (low aspect ratio) close more easily than equant pores. For a solid matrix $m$ of given Young's modulus $\left(E_{m}\right)$, the distribution of crack aspect ratios will determine the rate of crack closure with pressure, therefore it is expressed in the derivative of the stress-strain curve. Before the distribution of crack aspect ratios $\psi(\alpha)$ can be extracted, the proportion of the rock volume occupied by the crack network must be determined. This is known as the crack density $\Gamma$, a dimensionless parameter defined as $\Gamma=n c^{3} / V_{b}$ where $n$ is the number of oblate cracks with semimajor axis $c$ and $V_{b}$ is the total bulk volume of the sample (Jaeger et al. 2009).

Assuming that the porosity consists of thin, oblate ellipsoids lying parallel to bedding in an otherwise isotropic matrix, the material becomes transversely isotropic with respect to elastic properties. This is apart from any contribution to elastic anisotropy that might arise from preferred mineral orientations or mineral layering. This crack density can be calculated from only the compressional wave velocity parallel and perpendicular to the layering using the model of Cheng (1993), without having to determine the set of all five independent elastic constants required to characterize fully a transversely isotropic material (see Appendix). Figure 11 shows the measured velocities and those predicted from the model of Cheng (1993) for the crack densities given in Figure 11b. The model predicts well the change in the velocity perpendicular to the layering, but underestimates the rate of change in velocity parallel to the layering. This difference is most likely due to the fact that perfect alignment of the flat pores with the bedding plane was inferred from the contrasting pressure sensitivity of 
velocity in the two orientations, however there is likely to be some small angular spread of the pore orientations which would result in the observed slightly enhanced effect on the velocity parallel to layering. Also, for simplicity (and lacking the appropriate data), we have assumed the rock matrix to be isotropic, so that all the anisotropy measured is due to the oriented pores. The values chosen for the isotropic matrix bulk and shear moduli were selected from the values shown in Table 3, calculated for different aspect ratio pores using the self-consistent approach. The values that agree with our measured velocities are for pores of aspect ratio 0.07 . This aspect-ratio should be approximately equal to the aspect ratio of the majority of the porosity in the rock.

The crack density parameter $\Gamma$ refers to the density of cracks that are open at any given pressure, and is plotted as a function of confining pressure in Figure 11b. During all of the three separate loading cycles there is a steep decrease in crack density at confining pressures less than $20 \mathrm{MPa}$, followed by much slower decline between $20 \mathrm{MPa}$ and $90 \mathrm{MPa}$, suggesting that much of the crack closure takes place within the first $20 \mathrm{MPa}$ of loading. The initially lower aspect ratio (thinner) cracks would be expected to close at lower pressures, hence it is inferred that there must be a distribution of crack aspect ratios present. The predicted magnitude of crack density at any given pressure is dependent on the model used (Jaeger et al. 2009) and the approach described below provides only a first order estimate.

To determine the crack aspect ratio distribution, the method outlined in Section 10.4 of Jaeger et al. (2009) and further developed by David \& Zimmerman (2012) was adapted to incorporate crack density $(\Gamma)$ as determined by the method described by Cheng (1993) as outlined above. Therefore the method employed to estimate the aspect ratio distribution, which uses the way in which compressibility changes as a function of pressure, is written here in terms of how the crack density changes with pressure. The equation for closure pressure $P_{\text {close }}$ (as given in equation 20), therefore allows the aspect ratio $\alpha$ of cracks at the point of closing at pressure $P$ to be identified. If the density of open cracks $\Gamma(P)$ at pressure $P$ is known, the distribution of aspect ratios $\psi(\alpha)$ will be equal to $-\mathrm{d} \Gamma / \mathrm{d} \alpha$. The derivative of crack density as a function of pressure can be broken down using the chain rule to give:

$$
\frac{\mathrm{d} \Gamma}{\mathrm{d} P}=\frac{\mathrm{d} \Gamma}{\mathrm{d} \alpha} \frac{\mathrm{d} \alpha}{\mathrm{d} P} .
$$

The distribution of aspect ratios $\psi(\alpha)$ can therefore be written as 


$$
\psi(\alpha)=-\frac{\mathrm{d} \Gamma}{\mathrm{d} \alpha}=\frac{-\frac{\mathrm{d} \Gamma}{\mathrm{d} P}}{\frac{\mathrm{d} \alpha}{\mathrm{d} P}}
$$

$\mathrm{d} \alpha / \mathrm{d} P$ from equation 20 then gives

$$
\frac{\mathrm{d} \alpha}{\mathrm{d} P}=\frac{4\left(1-v_{m}^{2}\right)}{E_{m} \pi}
$$

so that

$$
\psi(\alpha)=\frac{-E_{m} \pi}{4\left(1-v_{m}^{2}\right)} \frac{\mathrm{d} \Gamma}{\mathrm{d} P}
$$

To avoid large fluctuations in the computed aspect ratio distribution, exponential curves of the form

$$
\Gamma=\Gamma_{0} \exp (-P / \widehat{P})
$$

were fitted to the crack density-pressure data and are shown in Figure 11b for three loading cycles on sample RC8. $\Gamma_{0}$ is the initial (zero pressure) crack density, and $\hat{P}$ is a characteristic crack-closing pressure related to aspect ratio $\hat{\alpha}$ by equation 20 The first derivative of the crack density with respect to the pressure can now be written

$$
\frac{\mathrm{d} \Gamma}{\mathrm{d} P}=\frac{-\Gamma_{0}}{\hat{P}} \exp \left(\frac{-P}{\hat{P}}\right)
$$

Substituting equation 20 into 26 so that

$$
\frac{\mathrm{d} \Gamma}{\mathrm{d} P}=\frac{-4\left(1-v_{m}^{2}\right) \Gamma_{0}}{E_{m} \pi \hat{\alpha}} \exp \left(\frac{-\alpha}{\hat{\alpha}}\right)
$$

gives the distribution of aspect ratios $\psi(\alpha)$ as

$$
\psi(\alpha)=\frac{E_{m} \pi}{4\left(1-v_{m}^{2}\right)} \frac{4\left(1-v_{m}^{2}\right) \Gamma_{0}}{E_{m} \pi \hat{\alpha}} \exp \left(\frac{-\alpha}{\hat{\alpha}}\right)
$$

which simplifies to 


$$
\psi(\alpha)=\frac{\Gamma_{0}}{\hat{\alpha}} \exp \left(\frac{-\alpha}{\hat{\alpha}}\right)
$$

Crack density is related to crack porosity $\phi_{c}$ by

$$
\phi_{c}=\frac{4 \pi \alpha}{3} \Gamma
$$

By assuming all the cracks in the rock are of the same radius, the distribution of crack porosity $z(\alpha)$ is given by:

$$
z(\alpha)=\frac{4 \pi \alpha}{3} \psi(\alpha)=4 \pi \Gamma_{0} \frac{\alpha}{\hat{\alpha}} \exp \left(\frac{-\alpha}{\hat{\alpha}}\right)
$$

The total crack porosity $\phi_{c}$ can then be found by integrating the above function:

$$
\begin{aligned}
& \phi_{c}=\int_{0}^{1} 4 \pi \Gamma_{0} \frac{\alpha}{\hat{\alpha}} \exp \left(\frac{-\alpha}{\hat{\alpha}}\right) \mathrm{d} \alpha \\
& \phi_{c}=4 \pi \Gamma_{0} \hat{\alpha}-4 \pi \Gamma_{0} \exp \left(\frac{-1}{\hat{\alpha}}\right)(1-\hat{\alpha})
\end{aligned}
$$

Figure 11c shows the aspect ratio distributions calculated from the change in crack density across different pressure ranges and for the three loading cycles on sample RC8. The modal aspect ratios and crack porosities are provided in Table 5. The aspect ratio distributions are similar to log-normal distributions with peaks on the order of $10^{-2}$, and crack porosity is $\sim 0.01$ if the data between 10 and $100 \mathrm{MPa}$ are used. It should be noted that although the absolute magnitude of the crack porosity is dependent upon the model used to calculate the effect of cracks on the elastic properties, the differences between the models do not result in orders of magnitude differences in crack porosity (Jaeger et al. 2009). These derived aspect ratio distributions will be used in the pore conductivity model below. 


\section{Pore conductivity model}

The measured pressure-dependent permeability of Whitby Mudstone was analysed further by considering flow conduits of elliptical cross-section. In the model, the pressure-dependent permeability is determined by three parameters: (i) the porosity of the conductive pore network, (ii) the aspect ratios of the conductive pores, and (iii) the width of the conductive pores.

First, following the approach of Seeburger \& Nur (1984), the axial volume flow rate $(Q)$ along a long cylindrical pore channel with elliptical cross section of aspect ratio $\alpha=b / c$, where $b$ is the half width and $c$ is the half length of the ellipse, is calculated as

$$
Q=\frac{\Delta P}{\Delta x} \frac{\pi}{4 \mu} \frac{b^{3} c^{3}}{b^{2}+c^{2}}
$$

(Lamb 1945). Applied pressure $\left(P_{\text {eff }}\right)$ causes an elastic change in pore width $(b)$, thus flow rate varies as a function of applied pressure as

$$
Q\left(P_{\mathrm{eff}}\right)=\frac{\Delta P}{\Delta x} \frac{\pi}{4 \mu} \frac{b_{0}^{3} c_{0}^{3}}{b_{0}^{2}+c_{0}^{2}}\left(1-\frac{2 P_{\mathrm{eff}} c_{0}\left(1-v^{2}\right)}{b_{0} E}\right)^{3}
$$

where $b_{0}$ and $c_{0}$ are the lengths of the half-axes of the ellipse at the reference pressure. Summing $N$ such channels present in cross sectional area $A_{\mathrm{t}}$ the total fluid flux $(J)$ is given by

$$
J\left(P_{\mathrm{eff}}\right)=\frac{\Delta P}{\Delta x} \frac{1}{A_{\mathrm{t}}} \frac{\pi}{4 \mu} \sum_{i=1}^{N} \frac{b_{i}^{3} c_{i}^{3}}{b_{i}^{2}+c_{i}^{2}}\left(1-\frac{2 P_{\mathrm{eff}} c_{i}\left(1-v^{2}\right)}{b_{i} E}\right)^{3}
$$

which, when compared to Darcy's law (equation 1), yields the pressure-dependent permeability $k$ of the conductive pore network:

$$
k\left(P_{\mathrm{eff}}\right)=\frac{\pi}{4 A_{\mathrm{t}}} \sum_{i=1}^{N} \frac{b_{i}^{3} c_{i}^{3}}{b_{i}^{2}+c_{i}^{2}}\left(1-\frac{2 P_{\mathrm{eff}} c_{i}\left(1-v^{2}\right)}{b_{i} E}\right)^{3}
$$


where $b_{i}$ and $c_{i}$ are dimensions of the $i^{\text {th }}$ pore. Assuming that the cracks have a constant initial width $b_{0}$ but a distribution of aspect ratios, the equation can be further simplified by substituting $c_{i}=b_{0} / \alpha_{i}$ to yield

$$
k\left(P_{\mathrm{eff}}\right)=\frac{\pi}{4 A_{\mathrm{t}}} \sum_{i=1}^{N} \frac{b_{0}^{4}}{\alpha_{i}^{3}+\alpha_{i}}\left(1-\frac{2 P_{\mathrm{eff}}\left(1-v^{2}\right)}{\alpha_{i} E}\right)^{3} .
$$

Whilst the flow is one-dimensional along the parallel axes of cylindrical channels of elliptical cross section, there is no imposed requirement that the ellipse long axes are parallel with each other, i.e. that the rock is transversely isotropic with respect to bedding. However, the use of a limited part of the $C_{i j}$ matrix determined from velocity measurements to estimate crack density necessarily implies that the cracks have a strong preferred orientation parallel to bedding. The principal aim of this model is only to estimate the pressure sensitivity of permeability for comparison with the measured value, not its absolute value.

A log-normal distribution of aspect ratios $(\alpha)$ was generated using a pseudo random number generator in MATLAB ${ }^{\circledR}$ (Matlab 2013) that changes with pressure (Figure 11d). The mean and variance of the aspect ratio distributions of crack-like pores which progressively close over the applied pressure range was set to that determined from the change in ultrasonic velocity with confining pressure (Figure 11a). The effective porosity of the conductive pore network at a given pressure was determined as follows. First, matrix elastic properties calculated using Voigt-Reuss-Hill averaging (Table 4) were used to predict pore volume strain when (i) most of the porosity is hosted within isolated, spherical pores and (ii) the remainder of the porosity (i.e. the conductive porosity) is hosted within elliptical pores with the log-normal aspect ratio distribution of the conductive crack network (Figure 11d). The measured pore volume strain data for samples RA13 and RA13 were then used to constrain the predicted behaviour by varying the proportions of these two components of the porosity (Figure 12a). With the aspect ratio distribution and conductive porosity set, the pore width was then varied to fit equation 36 to the permeability-effective pressure data from the compressibility measurements made on sample RA14 (Figure 12 a and b). The final conductive porosity values, aspect ratio distributions and pore widths used here are presented in Table 5, that show a strong similarity between crack porosity determined from ultrasonic velocity data and the conductive porosity determined using the pore conductivity model. These porosity values $(\sim 0.015)$ also match closely with the conductive porosity calculated 
from storativity $(\beta)$ measured on sample RA14 using the oscillating pore pressure technique $(\sim 0.02)$. The estimated conductive porosity is significantly less than the total porosity determined by helium pycnometry, thus empirically observed correlations between total porosity and permeability in mudstones are not generally likely to be meaningful, except insofar as conductive porosity may display some proportionality to total porosity.

The permeability model explored above is based on the narrowing and progressive closure of elliptical cross-section cylindrical conduits with applied pressure. The model does not take into consideration the fact that in a natural sample, if a crack becomes closed not only will that channel be removed from the flow network, but also any channels that it was connected to may also no longer be able to transmit fluid. This reduced connectivity will increase the tortuosity of the pathways to fluid flow, thus decreasing permeability further.

\section{Discussion}

\section{Permeability}

The results of permeability measurements on seven Whitby Mudstone samples are summarised in Table 2 and are within the range previously reported for other mudstones (Morrow et al. 1984; Katsube et al. 1991; Coyner et al. 1993; Schlömer \& Krooss 1997; Dewhurst et al. 1998; Kwon et al. 2001; Hildenbrand et al. 2004; Kwon et al. 2004; Yang \& Aplin 2007; Metwally \& Sondergeld 2011; Chalmers et al. 2012; Clarkson et al. 2012a; Ghanizadeh et al. 2014a; Ghanizadeh et al. 2014b; Heller et al. 2014; Morrow et al. 2014). All the samples tested showed the same permeability-effective pressure behaviour whereby initial pressurization causes an irreversible loss of permeability, after which a reproducible, non-linear pattern of permeability reduction with increasing effective pressure was observed. The dependence of permeability on effective pressure is simply but reasonably well described by an exponential relationship (equation 19) which incorporates the sensitivity of permeability to both confining pressure and pore pressure and accounts for the gas slippage effects detected at low pore pressures (<10 MPa).

\section{Microstructural controls on permeability}

The permeability of the Whitby Mudstone samples ranges between $3 \times 10^{-21} \mathrm{~m}^{2}$ and $2 \times 10^{-19} \mathrm{~m}^{2}$ (3 and $188 \mathrm{nD}$ ). Of the six samples oriented for flow parallel to layering, three have a permeability at a given pressure one order of magnitude higher than the others. This difference positively correlates with differences in silt content of the samples. The 
differences in permeability could also be explained by variations in bioturbation intensity observed at the mm-scale: The three higher permeability samples (RA1, RA2 and RA6) exhibit a more homogeneous host sediment containing isolated silt-filled burrows bearing high concentrations of pyrite (Figure 2a). Where packages of coarser grained sediment occur within a low permeability substrate, they have been shown to increase permeability (Pemberton \& Gingras 2005). The texture of the lower permeability samples (RA12, RA13 and RA14) is more mottled as both clay-filled and silt-filled burrows with gradational boundaries are distributed throughout the sample, and burrows show very little (if any) pyritization. These characteristics suggest that those samples have been subject to a higher degree of bioturbation, which can degrade the sorting characteristics of sediment hence leading to reduced permeability. There is some indication that the permeability variations correlate weakly with total porosity, although in the six samples measured the total porosity only varied between 7.2 and $8.7 \%$, whilst the permeability varied tenfold. If all the values of $k_{0}$ from the empirical fits given in Table 2 are fitted to a power-law where $k=C \phi^{n}$ a value of $n \sim 15$ is obtained.

The permeability of Whitby Mudstone parallel to layering is 60 times higher than the permeability normal to layering. Permeability anisotropy has been previously reported in clay and mica-bearing rocks such as mudstones and fault rocks (Dewhurst et al. 1996; Faulkner \& Rutter 1998; Yang \& Aplin 1998; Clennell et al. 1999; Kwon et al. 2004; Yang \& Aplin 2007) and is most likely due to the transversely isotropic mineralogic layering, grain shape and crystallographic preferred orientation fabric created during deposition, burial and diagenesis, or by mechanical shearing. Initial layering of silt rich and clay rich layers is produced during deposition and modified by bioturbation. This primary anisotropy is intensified with compaction, whereby detrital phyllosilicates mechanically rotate or recrystallize normal to the axial load (Clennell et al. 1999; Aplin et al. 2006; Day-Stirrat et al. 2008), deformable polygranular lithoclasts become flattened and initial pore spaces are flattened or removed. As well as reducing porosity and permeability, this change in particle orientation decreases flow path tortuosity parallel to the particle alignment direction and increases flow path tortuosity normal to the particle alignment (Arch \& Maltman 1990). The degree of anisotropy that results from this process in mudstones is strongly dependent on the ratio of quartz to clay content (Day-Stirrat et al. 2010). The non-platy habit of quartz grains means they do not develop a strong shape preferred orientation, but instead act as a supportive framework (where contiguous), sheltering areas of the clay matrix from effective 
pressure. Levels of anisotropy greater than 4 cannot be explained only by compaction induced fabrics, they must additionally be influenced by material heterogeneities (layering or banding) related to deposition (Yang \& Aplin 2007) and diagenesis leading to the formation of layering-parallel crack-like pores. In the Whitby Mudstone, both elongate mineral grains, granular clusters and microcracks show preferential alignment (Figure 2e) although the original depositional fabric has been mostly destroyed by bioturbation, leaving little evidence of primary lithological layering. Relict burrows, however, are oriented parallel to the bedding plane, hence where they are connected they may form a high-permeability network parallel to bedding.

\section{Comparison with pore images}

Permeability has been shown, both by the occurrence of gas slippage at pore pressures $<10 \mathrm{MPa}$ and by the pore conductivity modelling (equation 36), to be controlled by beddingparallel flat pores of nanometer-scale widths as inferred from seismic velocity measurements. Pores at the nm-scale were not imaged as part of this investigation, but some pore types in mudstones are universally found (Kwon et al. 2004; Schieber et al. 2010; Loucks et al. 2012) and can therefore be inferred from these other studies to exist also in Whitby Mudstone. The nanometre- to micrometre-scale matrix porosity in mudstones can be divided into three types: Interparticle pores, intraparticle pores and organic matter pores (intraparticle pores within organic matter) (Loucks et al. 2012). Kwon et al. (2004) suggested that low aspect ratio, crack-like pores associated with clay grain boundaries act as fluid conduits at low effective pressures, but at high effective pressures they are closed and permeability is controlled by less compliant, higher aspect ratio pores associated with terminations between mineral grain vertices. The latter are best developed in pressure shadows next to larger, more compactionresistant grains such as quartz, feldspar and pyrite, and they are well documented in a variety of mudstones by Schieber et al. (2010). Figure 2e shows an example of this textural feature in the Whitby Mudstone. It is likely these pores act as storage pores, only enhancing permeability where they form part of a connected network. Schieber et al. (2010) showed that phyllosilicate framework pores are the most ubiquitous type in all samples, and within mudstones with low TOC (total organic carbon) a large proportion are open and likely to be connected. Using a combination of X-ray computed tomography and serial block face scanning electron microscopy, Ma et al. (2016) produced 3D images of pore networks comprising intra-organic pores, organic interface pores, intraparticle pores and inter-mineral pores at resolutions between $7.7 \mu \mathrm{m}$ and $7 \mathrm{~nm}$. Pores were found to have a bimodal size 
distribution with peaks at $0.2 \mu \mathrm{m}$ and $0.04 \mu \mathrm{m}$, and at scales $>20 \mathrm{~nm}$ pores show no apparent connectivity. Permeability was therefore attributed to fluid transport through the connected matrix of organic matter and clay minerals via pores which are below the imaging scale. The present study, however, implies that a substantial part of the conduction-controlling porosity may lie at length scales near or even below the limit of what has been previously resolved in imaging studies.

The pore network within the Whitby Mudstone inferred from measurements of velocity, pore volume strain and permeability could be explained by the characteristic pores types described by Kwon et al. (2001), Schieber (2011), Loucks et al. (2012) and Ma et al. (2016), and is illustrated schematically in Figure 13. The stiffer, blind-ending storage pores constitute most of the porosity and are most likely associated with terminations between clay and silt grains, pressure shadows around silt grains and relict burrows with coarse-grained infills. The inferred bedding-parallel, crack-like, fluid conducting pores constitute $\sim 1 / 4$ of the total porosity, are connected in the plane of bedding, and tend to be associated with weakly bonded grain boundaries.

\section{Sensitivity of permeability to confining pressure}

The observed irreversible reduction of permeability upon initial pressurization is attributed to inelastic closure of secondary microcracks that may have formed during depressurization, and/or sample preparation. This characteristic of permeability behaviour was reported by several authors for clay bearing rocks (Katsube \& Coyner 1994; Dewhurst et al. 1998; Faulkner \& Rutter 1998; Kwon et al. 2004), demonstrating that pressure cycling recovers depressurization (expansion) damage and returns the permeability-effective pressure behaviour to its state at the depth corresponding to the maximum pressure applied. Measurements at different effective pressure ranges (Figure 8) demonstrate that the extent of recovery is dependent upon the maximum pressure applied to the sample. This implies that the permeability of argillaceous units within sedimentary basins may depend on burial history (including pore pressure evolution) as well as current loading conditions (Kwon et al. 2004), i.e. they can become under-, over- or normally-consolidated. For example, erosion and unloading of mudstones will decrease effective pressure, but permeability may not rebound to earlier, higher values, leaving the rock in an overconsolidated state.

After pressure cycling, the sensitivity of permeability to externally applied confining pressure is described by $\gamma$ in equation 19 , which ranges between -0.02 and $-0.04 \mathrm{MPa}^{-1}$ for all the 
samples tested here with the exception of RA12 which has a $\gamma$ value of $0.009 \mathrm{MPa}^{-1}$. The value of $\gamma$ reflects the elastic response of the interconnected pore network to hydrostatic pressure change. Depending on their elastic properties, flow channels can narrow or become pinched closed with increasing pressure and the rate at which this occurs controls the rate of permeability loss. A high rate of permeability loss (high $\gamma$ ) can be attributed to the narrowing or removal of the more compressible pores from the fluid conducting network. Although $\gamma$ has not been found to differ greatly between the Whitby Mudstone samples, it can be expected to vary with mineralogy of different rock types (particularly clay content (Chalmers et al. 2012; Ghanizadeh et al. 2014a; Ghanizadeh et al. 2014b; Ghanizadeh et al. 2015) and microstructure.

\section{Sensitivity of permeability to pore pressure}

For all samples of Whitby Mudstone tested, permeability showed a higher sensitivity to confining pressure than to equivalent changes in pore pressure, yielding values of $\chi<1$ (0.42 to 0.97, Table 2) and is consistent with theoretical values of $\chi$ for poroelasticity (Biot 1941) and to other measurements on shale (Heller et al. 2014). Kwon et al. (2001) showed that for a model of a clay-rich mudstone where clays form a connected, load-supporting matrix, pore dimensions will be similarly affected by confining pressure and pore pressure, thus $\chi$ is expected to be close to unity. In 2D microscope images Whitby Mudstone samples appear to be clay-matrix supported (Figure 2c), with isolated silt grains, which could explain values of $\chi$ close to 1 . The variability in $\chi$ measured here may reflect differences in the connectivity of silt grains that lie out of the plane of a thin-section.

The presence of gas-slippage effects within the Whitby Mudstone is shown here to be restricted to pore pressures below $10 \mathrm{MPa}$. It is important to account for this transition, because during the later stages of shale gas production, flow may take place at very low pore pressures. Because the occurrence of gas slippage is dependent on pore diameter, the pore pressure at which flow regime changes from Darcy to slip flow can be used to estimate pore diameter. As shown by Randolph et al. (1984), rearrangement of the modified Poiseuille's law (Poiseuille's equation for viscous flux through a slit-shaped pore combined with Klinkenberg's equation for Darcy + Knudsen flow) allows us to estimate the effective aperture of flow paths from the $K_{b}$ value:

$$
w=\frac{16 \varsigma \mu}{K_{b}}\left(\frac{2 \mathrm{R} T}{\pi M}\right)
$$


where $w$ is slit width (m), $\varsigma$ is an empirical constant (approximately unity), $\mu$ is gas viscosity (Pa s), $\mathrm{R}$ is the gas constant, $T$ is temperature $(\mathrm{K}), M$ is molar mass $(\mathrm{kg})$ and $K_{b}$ is the Klinkenberg parameter (Pa). For sample RA2 of Whitby Mudstone, this gives an average slit width of $41 \mathrm{~nm}$, which is 10 times higher than that estimated by fitting the pore conductivity model to the permeability data for sample RA14 (Table 5).

\section{Acoustic wave velocity}

Sensitivity of ultrasonic velocity to effective pressure was measured on core plugs of Whitby Mudstone with their cylinder axes oriented normal and parallel to layering. The data show an increase of ultrasonic velocity with confining pressure as well as hysteretic loading/ unloading behaviour. A permanent increase in velocity after the first pressure cycle was also observed for the normal to layering orientation, which is inferred to correspond to the permanent decrease in permeability that occurs during the initial pressure cycle.

\section{Velocity hysteresis}

Seismic velocity hysteresis has previously been attributed to several processes, including irreversible partial or full closure of microcracks (Birch 1960), irreversible compaction of pore spaces especially in rocks with a highly compressible clay matrix (Jones \& Wang 1981) and smoothing of ductile asperities on crack surfaces, thereby increasing contact surface area (Ji et al. 2007). From the observed hysteretic velocity behaviour, it can be said firstly that crack surfaces pushed into contact during loading do not re-open at the same rate during unloading, possibly due to friction between crack surfaces. Secondly, some of the crack surfaces that were pushed into contact during the initial loading cycle remain permanently closed. This could be due to molecular adhesion plasticity of crack surfaces, wearing of asperities causing an increase in surface area and thus friction, and/or grain rearrangement.

\section{Pore network}

The nature of the pore network controlling pressure-dependent permeability was analysed further by modelling based on the pressure-dependent conductivity of elliptical cross section cylindrical pore channels. The parameters used in the model, namely conductive porosity, aspect ratio distribution and pore width distribution, were estimated from pore volume-strain data, ultrasonic velocity data and permeability-effective pressure data respectively. These values are presented in Table 5. Using the aspect ratio distribution of the crack network 
determined from ultrasonic velocity data, the porosity of this crack network was also extracted using equation 36 and matches closely with the conductive porosity obtained from the pore conductivity model ( $\sim 0.015$, Table 5$)$. Furthermore, the storativity $(\beta)$ measured with the pore pressure oscillation technique was used to calculate the conductive porosity, giving a value for sample RA14 of 0.023. These results all suggest that the conductive porosity in the Whitby Mudstone is only a small fraction of the total porosity of 0.08 .

The sensitivity of permeability to effective pressure is a result of changes forced upon the geometry and connectivity of the conductive pore network. It has been shown that by modelling these pores as a distribution of parallel, narrow channels of elliptical cross-section that progressively close with applied stress, changes in measured elastic moduli of the rock with pressure can be used to describe their geometry using a distribution of aspect ratios which is similar to a log-normal distribution. The rate at which permeability decreases with hydrostatic pressure is dependent on the mean and variance of this distribution, because lower aspect ratio pores close more easily with applied pressure, thereby reducing the width and connectivity of the conductive pore network. Measurements of total pore volume strain indicate that the greater fraction of the porosity, which does not contribute to fluid transport, is hosted within pores which are much less sensitive to pressure and are therefore interpreted as having much higher aspect ratios, close to 1 (i.e. spherical pores). The modal value of the pore width distribution obtained from fitting equation 36 to permeability data is very low ( $\sim 0.6 \mathrm{~nm}$ ) compared with the pore width obtained from the Klinkenberg parameter, which is around $41 \mathrm{~nm}$. This difference is most likely due to the fact that the simple, straight pore geometry assumed for this conductivity model is not unique. It does not account for tortuosity of the fluid pathways and variations in channel geometry along the flow paths, but instead compensates for observed low permeability by predicting narrower fluid pathways.

Based on these observations it is proposed that most of the pore volume is hosted within high aspect ratio 'storage' pores which would show very little pressure sensitivity of permeability and do not contribute to, or control fluid transport. There is no simple relationship expected between permeability and total porosity. Permeability is controlled by a linked network of crack-like flow channels with low aspect ratios. These connective cracks progressively close elastically under pressure, increasing flow path tortuosity and reducing permeability of Whitby Mudstone by up to one order of magnitude over the pressure range explored. By high effective pressures (>60 MPa), flow becomes restricted to be within a network of poorly 
connected, higher aspect ratio, stiffer pores, hence the progressively-decreasing sensitivity of permeability to pressure and increasing values of elastic stiffness.

\section{Application to reservoir models}

When building a well-test interpretation model, it is common to assume that permeability remains constant with changes in effective pressure, because laboratory-determined coefficients to describe pressure-dependent permeability, measured as demonstrated herein, are usually not available. While this assumption may be reasonable for conventional reservoirs where pore throat diameters are large and relatively insensitive to changes in pressure, for unconventional reservoirs where pore throat diameters are sub-micron in size, changes in effective pressure can have much greater implications for fluid transport. As reservoir production takes place, gas pressure drawdown increases the in-situ effective pressure and a decrease in permeability ensues. If the rock is more sensitive to pore pressure than to confining pressure changes, as may be the case for some mudstones, then permeability will decrease even more with pore pressure drawdown than predicted by a simple Terzaghi effective pressure law $\left(P_{e f f}=P_{c}-P_{p}\right)$ (Terzaghi 1923). To demonstrate this effect, (Mckernan et al. 2014) used a reservoir simulation model (GASSIM, Lee \& Wattenbarger 1996) to compare production rate estimates from a reservoir with pressureinsensitive permeability with those from a reservoir with pressure sensitivity of permeability defined by equation 16. The results show that at low bottom-hole pressures, when pressure sensitivity of permeability is taken into account, the production rate decreases more rapidly and during the later stages of production it is almost half that predicted using pressureindependent permeability. Mckernan et al. (2014) only used Terzaghi effective pressure but the inclusion of the effective pressure coefficient $\chi$ will not have a major effect unless it departs substantially from unity. Assumption of pressure-independent permeability also severely reduces the estimate of original gas in place. If unconventional reservoir models used to interpret well-tests do not take into account pressure-sensitivity then erroneous inferences will be made of permeability, gas in place and expected productivity.

\section{Conclusions}

Measured permeability of dried Whitby Mudstone ranges between $7 \times 10^{-21} \mathrm{~m}^{2}$ to $2 \times 10^{-19} \mathrm{~m}^{2}$ (7 nd to $188 \mathrm{nd}$ ) and is within the range of previously measured values for clay-rich rocks. Initial pressurization causes an irreversible loss of permeability of up to 1.5 orders of magnitude, after which a reproducible, non-linear pattern of permeability reduction with 
increasing effective pressure is observed. This demonstrates the absolute need for pressure cycling to be applied to recover the sample to its state at depth before representative in-situ permeability can be usefully measured. Pressure cycling to different maximum effective pressures showed that the extent of recovery is dependent upon amount of pressure applied to the sample, implying that the permeability of mudstones depends on burial history as well as current loading conditions. Whitby Mudstone showed a higher sensitivity of permeability to confining pressure than to pore pressure, yielding permeability effective pressure coefficients $\chi<1$ (0.42 to 0.97$)$. Gas slippage effects are shown to be restricted to pore pressures below $10 \mathrm{MPa}$ hence do not affect the permeability measurements over the greater part of the pore and confining pressure ranges studied.

After pressure cycling, the dependence of Whitby Mudstone permeability on effective pressure is satisfactorily described for engineering purposes by an exponential relationship which incorporates the sensitivity of permeability to both confining pressure and pore pressure and accounts for the gas slippage effects detected at pore pressures $<10 \mathrm{MPa}$. If analysis of well test results does not take into account the sensitivity of permeability to both confining pressure and pore pressure, then substantial overestimations of projected gas flow rate and original gas in place could made.

The magnitude of permeability is affected by the degree of bioturbation. Where burrows form coarse grained packages in a fine grained matrix, permeability will be enhanced; when bioturbation homogenises the sediment, destroying layering and pre-existing burrows, permeability will be decreased. Permeability and its pressure sensitivity is also expected to be influenced by partial saturation with liquids, although this aspect of behaviour was not investigated in the present study.

Permeability anisotropy is marked in the Whitby Mudstone $\left(k_{\text {parallel }}=60 \times k_{\text {normal }}\right)$ and is attributed to both the bedding-parallel preferred orientation of elongate mineral clusters and cracks along grain boundaries, as well as the presence of high permeability laminae and relict (flattened) burrows which increase permeability along the layering.

Based on changes in crack density, permeability and bulk volume with effective pressure, it is inferred that in the Whitby Mudstone most of the pore volume is hosted within high aspect ratio storage pores that control bulk compressibility but have little effect on permeability. At low effective pressures, permeability is controlled by a network of long, thin crack-like pores with aspect ratios 10 to 100 times smaller. These connective cracks progressively close with 
pressure, reducing permeability of Whitby Mudstone by up to one order of magnitude over the range of reservoir pressures. At higher effective pressures, fluid is progressively restricted to flowing through the less well connected network of higher aspect ratio, stiffer pores. As the shape of these pores is less sensitive to pressure, so too becomes the permeability. Assuming that in mudstones permeability is enhanced by a network of cracklike pores that progressively close under pressure, measured changes in elastic moduli with pressure can potentially be used as a tool for predicting the sensitivity of permeability to effective pressure.

\title{
Acknowledgements
}

This work was supported by a UK NERC CASE research studentship to RM, with Shell as CASE partners, and by UK NERC grant NE/M001458/1. Ronny Hofman and Calum Macaulay from Shell are thanked for supporting this project. We thank experimental officer Stephen May for equipment maintenance and specimen fabrication. Dr Kate Brodie is thanked for help collecting and processing the SEM data. Joerg Renner and Alexandra Amann-Hildenbrand are thanked for their detailed reviews that led to considerable improvement to the quality of this paper. We would also like to thank editor Rick Law for his patience in dealing with this manuscript.

\section{Nomenclature}

\author{
$J_{i j}, J \quad$ Fluid flux $\left(\mathrm{ms}^{-1}\right)$. \\ $k_{i j}, k$ Permeability $\left(\mathrm{m}^{2}\right)$. \\ $\mu \quad$ Fluid viscosity (Pa s). \\ $\nabla P \quad$ Pressure gradient $\left(\mathrm{Pa} \mathrm{m}^{-1}\right)$. \\ $P_{1} \quad$ Upstream pore pressure $(\mathrm{Pa})$. \\ $P_{2} \quad$ Downstream pore pressure $(\mathrm{Pa})$. \\ $L \quad$ Sample length (m). \\ $k_{a} \quad$ Apparent permeability $\left(\mathrm{m}^{2}\right)$. \\ $k_{\infty} \quad$ True permeability $\left(\mathrm{m}^{2}\right)$. \\ $m$ Dimensionless constant in the gas slippage equation. \\ $\lambda \quad$ Mean free path of a gas (m).
}


c Capillary radius (m).

$K_{b} \quad$ Klinkenberg parameter $\left(\mathrm{Pa}^{-1}\right)$.

$P_{p} \quad$ Pore pressure (Pa).

$\sigma_{i j} \quad$ Stress tensor $(\mathrm{Pa})$.

$\sigma_{i j}^{\text {eff }} \quad$ Effective stress tensor $(\mathrm{Pa})$.

$\chi \quad$ Effective pressure coefficient.

$\delta_{i j} \quad$ Kronecker delta.

$\phi \quad$ Porosity.

$V_{b} \quad$ Bulk volume of the sample $\left(\mathrm{m}^{3}\right)$.

$V_{g} \quad$ Grain volume of the sample $\left(\mathrm{m}^{3}\right)$.

$\eta \quad$ Dimensionless permeability.

$\xi \quad$ Dimensionless storativity.

$S \quad$ Cross sectional area of the sample $\left(\mathrm{m}^{2}\right)$.

$T \quad$ Period of oscillations (s).

$\beta_{D} \quad$ Downstream storage $\left(\mathrm{m}^{3} \mathrm{~Pa}^{-1}\right)$.

$\beta \quad$ Sample storativity $\left(\mathrm{Pa}^{-1}\right)$.

A Amplitude ratio of upstream and downstream pressure waves.

$\theta \quad$ Phase shift of downstream wave relative to upstream (rad).

$C_{f} \quad$ Fluid compressibility $\left(\mathrm{Pa}^{-1}\right)$.

$C_{p} \quad$ Compressibility of porosity to changes in pore pressure at constant confining pressure $\left(\mathrm{Pa}^{-1}\right)$.

$\omega \quad$ Exponential decay parameter $\left(\mathrm{s}^{-1}\right)$.

$\Delta P_{u} \quad$ Initial pressure difference between upstream and downstream pressures $(\mathrm{Pa})$.

$V_{u} \quad$ Volume of upstream reservoir $\left(\mathrm{m}^{3}\right)$.

$V_{d} \quad$ Volume of downstream reservoir $\left(\mathrm{m}^{3}\right)$.

$V_{p} \quad$ Pore volume of sample $\left(\mathrm{m}^{3}\right)$.

$p \quad$ Ratio of pore volume to upstream volume.

$q \quad$ Ratio of pore volume to downstream volume.

$f_{1}$ Factor to account for non-zero porosity in pulse-transient permeability measurement.

$\vartheta \quad$ Solutions to transcendental function (rad).

$k_{0} \quad$ Permeability at zero pressure $\left(\mathrm{m}^{2}\right)$. 
$\gamma \quad$ Empirical coefficient that describes pressure dependence of permeability $\left(\mathrm{Pa}^{-1}\right)$.

$P_{\text {eff }} \quad$ Effective pressure $(\mathrm{Pa})$.

$n \quad$ Effective pressure exponent.

F Empirical constant for power-law (Pa).

$P_{\text {close }} \quad$ Pressure required to close an elliptical pore (Pa).

$E_{m}, E$ Young's modulus (Pa).

$\alpha_{0} \quad$ Aspect ratio of pore (short / long).

$v_{m}, v$ Poisson's ratio.

$\Gamma \quad$ Crack density.

$\psi \quad$ Probability distribution function of aspect ratios.

$\Gamma_{0} \quad$ Crack density at zero pressure.

$\hat{\alpha} \quad$ Characteristic pore aspect ratio.

$\hat{P} \quad$ Characteristic crack closure pressure $(\mathrm{Pa})$.

$\phi_{c} \quad$ Crack porosity.

Z Probability distribution function of crack porosity.

$Q \quad$ Volumetric flow rate $\left(\mathrm{m}^{3} \mathrm{~s}^{-1}\right)$.

$x \quad$ Flow path length (m).

$c_{0}, c_{i} \quad$ Long axis of elliptical shaped pores. Subscripts indicate zero pressure and $i^{\text {th }}$ pore channel respectively.

$b_{0}, b_{i}$ Short axis of elliptical shaped pores. Subscripts indicate zero pressure and $i^{\text {th }}$ pore channel respectively.

$A_{t} \quad$ Total cross sectional area.

$i \quad$ The index of the $i^{\text {th }}$ pore channel.

$N \quad$ Total number of pore channels.

w Pore channel width calculated from Klinkenberg parameter (m).

$\varsigma \quad$ Empirical constant.

$\mathrm{R} \quad$ Gas constant $\left(\mathrm{J} \mathrm{mol}^{-1} \mathrm{~K}^{-1}\right)$.

$T$ Absolute temperature (K).

M Molar Mass (kg).

$C_{i j}^{0} \quad$ Voigt elastic stiffness matrix of uncracked rock (Pa).

$C_{i j}^{*} \quad$ Voigt elastic stiffness matrix of cracked rock (Pa).

$C_{i j}^{1}, C_{i j}^{2} \quad$ First and second order terms in expansion crack density dependent elasticity. 
$a_{i j}, b_{i j} \quad$ Terms in Cheng (1993) equations.

$U_{1,2,3}$ Terms in Cheng (1993) equations.

M Term in Cheng (1993) equations.

$\kappa \quad$ Term in Cheng (1993) equations.

$\lambda \quad$ Lamé elastic constant (Pa).

$\mu, \mu^{\prime} \quad$ Shear modulus of matrix and weak phase respectively (Pa).

$K, K^{\prime} \quad$ Bulk modulus of matrix and weak phase respectively (Pa).

$V_{p} \quad$ Compressional wave velocity $\left(\mathrm{ms}^{-1}\right)$.

$V_{S} \quad$ Shear wave velocity $\left(\mathrm{ms}^{-1}\right)$. 


\section{References}

Al-Wardy, W. \& Zimmerman, R.W. 2004. Effective stress law for the permeability of clayrich sandstones. Journal of Geophysical Research: Solid Earth, 109, B04203, doi: 10.1029/2003JB002836.

Aplin, A.C., Matenaar, I.F., McCarty, D.K. \& van Der Pluijm, B.A. 2006. Influence of mechanical compaction and clay mineral diagenesis on the microfabric and pore-scale properties of deep-water Gulf of Mexico mudstones. Clays and Clay Minerals, 54, 500514.

Arch, J. \& Maltman, A. 1990. Anisotropic permeability and tortuosity in deformed wet sediments. Journal of Geophysical Research: Solid Earth, 95, 9035-9045.

Bernabe, Y. 1987. The effective pressure law for permeability during pore pressure and confining pressure cycling of several crystalline rocks. Journal of Geophysical Research: Solid Earth, 92, 649-657, doi: 10.1029/JB092iB01p00649.

Bernabé, Y. 1986. The effective pressure law for permeability in Chelmsford granite and Barre granite. International Journal of Rock Mechanics and Mining Sciences \& Geomechanics Abstracts, 23, 267-275.

Bernabé, Y. 1988. Comparison of the effective pressure law for permeability and resistivity formation factor in Chelmsford granite. Pure and Applied Geophysics, 127, 607-625.

Bernabé, Y., Mok, U. \& Evans, B. 2006. A note on the oscillating flow method for measuring rock permeability. International Journal of Rock Mechanics and Mining Sciences, 43, 311-316.

Berryman, J.G. 1992. Effective stress for transport properties of inhomogeneous porous rock. Journal of Geophysical Research: Solid Earth, 97, 17409-17424, doi: 10.1029/92JB01593.

Berryman, J.G. 1995. Mixture theories for rock properties. In: Ahrens, T.J. (ed.) Rock physics and phase relations: a handbook of physical constants. American Geophysical Union, Washington, DC, 205-228.

Bevington, P.R. \& Robinson, D.K. 1992. Data reduction and error analysis for the physical sciences. McGraw-Hill, New York.

Biot, M.A. 1941. General theory of three-dimensional consolidation. Journal of applied physics, 12, 155-164.

Birch, F. 1960. The velocity of compressional waves in rocks to 10 kilobars: 1 . Journal of Geophysical Research, 65, 1083-1102.

Blatt, H. 1992. Sedimentary petrology. 2nd ed. Freeman, New York.

Brace, W.F., Walsh, J.B. \& Frangos, W.T. 1968. Permeability of granite under high pressure. Journal of Geophysical Research, 73, 2225-2236.

Burke, M.M. \& Fountain, D.M. 1990. Seismic properties of rocks from an exposure of extended continental crust: New laboratory measurements from the Ivrea Zone. Tectonophysics, 182, 119-146.

Bush, D.C., Jenkins, R.E. \& others. 1970. Proper hydration of clays for rock property determinations. Journal of Petroleum Technology, 22, 800-804.

Bustin, R.M., Bustin, A.M.M., Cui, A., Ross, D., Pathi, V.M. \& others. 2008. Impact of shale properties on pore structure and storage characteristics. SPE shale gas production conference.

Chalmers, G.R.L., Ross, D.J.K. \& Bustin, R.M. 2012. Geological controls on matrix permeability of Devonian Gas Shales in the Horn River and Liard basins, northeastern British Columbia, Canada. International Journal of Coal Geology, 103, 120-131.

Cheng, C.H. 1993. Crack models for a transversely isotropic medium. Journal of Geophysical Research: Solid Earth, 98, 675-684, doi: 10.1029/92JB02118. 
Clarkson, C.R., Jensen, J.L., Pedersen, P.K. \& Freeman, M. 2012a. Innovative methods for flow-unit and pore-structure analyses in a tight siltstone and shale gas reservoir. AAPG Bulletin, 96, 355-374.

Clarkson, C.R., Nobakht, M., Kaviani, D. \& Ertekin, T. 2012b. Production Analysis of TightGas and Shale-Gas Reservoirs Using the Dynamic-Slippage Concept. doi: 10.2118/144317-PA.

Clennell, M.B., Dewhurst, D.N., Brown, K.M. \& Westbrook, G.K. 1999. Permeability anisotropy of consolidated clays. Geological Society, London, Special Publications, 158, 79-96.

Coyner, K., Katsube, T.J., Best, M.E. \& Williamson, M. 1993. Gas and water permeability of tight shales from the venture gas field, offshore Nova Scotia. Papers - Geological Survey of Canada, 129-129.

Coyner, K.B. 1984. Effects of stress, pore pressure, and pore fluids on bulk strain, velocity, and permeability in rocks. $\mathrm{PhD}$, Massachusetts Institute of Technology.

Cui, X., Bustin, A.M.M. \& Bustin, R.M. 2009. Measurements of gas permeability and diffusivity of tight reservoir rocks: different approaches and their applications. Geofluids, 9, 208-223.

David, E.C. \& Zimmerman, R.W. 2012. Pore structure model for elastic wave velocities in fluid-saturated sandstones. Journal of Geophysical Research: Solid Earth, 117, B07210, doi: 10.1029/2012JB009195.

Day-Stirrat, R.J., Aplin, A.C., rodo, J. \& Van der Pluijm, B.A. 2008. Diagenetic reorientation of phyllosilicate minerals in Paleogene mudstones of the Podhale Basin, southern Poland. Clays and Clay Minerals, 56, 100-111.

Day-Stirrat, R.J., Dutton, S.P., Milliken, K.L., Loucks, R.G., Aplin, A.C., Hillier, S. \& Van Der Pluijm, B.A. 2010. Fabric anisotropy induced by primary depositional variations in the silt: clay ratio in two fine-grained slope fan complexes: Texas Gulf Coast and northern North Sea. Sedimentary Geology, 226, 42-53.

Dewhurst, D.N., Aplin, A.C., Sarda, J.-P. \& Yang, Y. 1998. Compaction-driven evolution of porosity and permeability in natural mudstones: An experimental study. Journal of Geophysical Research: Solid Earth, 103, 651-661.

Dewhurst, D.N., Brown, K.M., Clennell, M.B. \& Westbrook, G.K. 1996. A comparison of the fabric and permeability anisotropy of consolidated and sheared silty clay. Engineering Geology, 42, 253-267.

Dicker, A.I. \& Smits, R.M. 1988. A Practical Approach for Determining Permeability From Laboratory Pressure-Pulse Decay Measurements. Society of Petroleum Engineers, 285292.

Faulkner, D.R. \& Rutter, E.H. 1998. The gas permeability of clay-bearing fault gouge at $20^{\circ}$ C. Geological Society, London, Special Publications, 147, 147-156.

Faulkner, D.R. \& Rutter, E.H. 2000. Comparisons of water and argon permeability in natural clay-bearing fault gouge under high pressure at $20^{\circ}$ C. Journal of Geophysical Research: Solid Earth, 105, 16415-16426.

Fischer, G.J. 1992. The determination of permeability and storage capacity: Pore pressure oscillation method. In: Evans, B. \& Wong, T.f. (eds.) Fault mechanics and transport properties of rocks. New York: Academic Press, 187-212.

Gangi, A.F. 1978. Variation of whole and fractured porous rock permeability with confining pressure. International Journal of Rock Mechanics and Mining Sciences \& Geomechanics Abstracts, 15, 249-257, doi: http://dx.doi.org/10.1016/01489062(78)90957-9.

Ghadeer, S. 2011. An investigation of the sediment dispersal operating to control lithofacies variability and organic carbon preservation in an ancient mud-dominated succession: 
a case study of the Lower Jurassic mudstone dominated succession exposed in the Cleveland Basin (North Yorkshire). PhD, University of Manchester.

Ghadeer, S.G. \& Macquaker, J.H.S. 2011. Sediment transport processes in an ancient muddominated succession: a comparison of processes operating in marine offshore settings and anoxic basinal environments. Journal of the Geological Society, 168, 1121-1132.

Ghanizadeh, A., Amann-Hildenbrand, A., Gasparik, M., Gensterblum, Y., Krooss, B.M. \& Littke, R. 2014a. Experimental study of fluid transport processes in the matrix system of the European organic-rich shales: II. Posidonia Shale (Lower Toarcian, northern Germany). International Journal of Coal Geology, 123, 20-33.

Ghanizadeh, A., Bhowmik, S., Haeri-Ardakani, O., Sanei, H. \& Clarkson, C.R. 2015. A comparison of shale permeability coefficients derived using multiple non-steady-state measurement techniques: Examples from the Duvernay Formation, Alberta (Canada). Fuel, 140, 371-387.

Ghanizadeh, A., Gasparik, M., Amann-Hildenbrand, A., Gensterblum, Y. \& Krooss, B.M. 2014b. Experimental study of fluid transport processes in the matrix system of the European organic-rich shales: I. Scandinavian Alum Shale. Marine and Petroleum Geology, 51, 79-99.

Gosman, A., McCarty, R.D. \& Hust, J.G. 1969. Thermodynamic properties of argon from the triple point to $300 \mathrm{~K}$ at pressures to 1000 atmospheres. National Standard Reference Data Series, National Bureau of Standards Report 27, U.S. Department of Commerce, Washington DC.

Heller, R., Vermylen, J. \& Zoback, M. 2014. Experimental investigation of matrix permeability of gas shales. AAPG Bulletin, 98, 975-995.

Hildenbrand, A., Schlömer, S., Krooss, B.M. \& Littke, R. 2004. Gas breakthrough experiments on pelitic rocks: comparative study with N2, CO2 and CH4. Geofluids, 4, 61-80, doi: 10.1111/j.1468-8123.2004.00073.x.

Hudson, J.A. 1980. Overall properties of a cracked solid. Mathematical Proceedings of the Cambridge Philosophical Society, 88, 371-384, doi: 10.1017/S0305004100057674.

Hudson, J.A. 1981. Wave speeds and attenuation of elastic waves in material containing cracks. Geophysical Journal of the Royal Astronomical Society, 64, 133-150, doi: 10.1111/j.1365-246X.1981.tb02662.x.

Jaeger, J.C., Cook, G.W. \& Zimmerman, R. 2009. Fundamentals of rock mechanics. Blackwell, Oxford.

Ji, S., Wang, Q., Marcotte, D., Salisbury, M.H. \& Xu, Z. 2007. P wave velocities, anisotropy and hysteresis in ultrahigh-pressure metamorphic rocks as a function of confining pressure. Journal of Geophysical Research: Solid Earth, 112, B09204, doi: 10.1029/2006JB004867.

Jones, L.E.A. \& Wang, H.F. 1981. Ultrasonic velocities in Cretaceous shales from the Williston basin. Geophysics, 46, 288-297.

Katsube, T.J. \& Coyner, K. 1994. Determination of permeability-compaction relationship from interpretation of permeability-stress data for shales from eastern and northern Canada. Geological Survey of Canada: Current Research, 1994-D, 169-178.

Katsube, T.J., Mudford, B.S. \& Best, M.E. 1991. Petrophysical characteristics of shales from the Scotian shelf. Geophysics, 56, 1681-1689.

Kemp, S.J., Merriman, R.J. \& Bouch, J.E. 2005. Clay mineral reaction progress--the maturity and burial history of the Lias Group of England and Wales. Clay minerals, 40, 43-61.

Klinkenberg, L.J. 1941. The Permeability Of Porous Media To Liquids And Gases. Drilling and Production Practice API, 200-213.

Kranz, R.L., Saltzman, J.S. \& Blacic, J.D. 1990. Hydraulic diffusivity measurements on laboratory rock samples using an oscillating pore pressure method. International 
Journal of Rock Mechanics and Mining Sciences \& Geomechanics Abstracts, 27, 345352, doi: http://dx.doi.org/10.1016/0148-9062(90)92709-N.

Kwon, O., Kronenberg, A.K., Gangi, A.F. \& Johnson, B. 2001. Permeability of Wilcox shale and its effective pressure law. Journal of Geophysical Research: Solid Earth, 106, 19339-19353.

Kwon, O., Kronenberg, A.K., Gangi, A.F., Johnson, B. \& Herbert, B.E. 2004. Permeability of illite-bearing shale: 1 . Anisotropy and effects of clay content and loading. Journal of Geophysical Research: Solid Earth, 109, B10205, doi: 10.1029/2004JB003052.

Lamb, H. 1945. Hydrodynamics. 6th ed. Dover publications, New York.

Lee, J. \& Wattenbarger, R.A. 1996. Gas reservoir engineering. Society of Petroleum Engineers.

Letham, E.A. \& Bustin, R.M. 2016. Klinkenberg gas slippage measurements as a means for shale pore structure characterization. Geofluids, 16, 264-278, doi: 10.1111/gfl.12147.

Loucks, R.G., Reed, R.M., Ruppel, S.C. \& Hammes, U. 2012. Spectrum of pore types and networks in mudrocks and a descriptive classification for matrix-related mudrock pores. AAPG Bulletin, 96, 1071-1098.

Ma, L., Taylor, K.G., Lee, P.D., Dobson, K.J., Dowey, P.J. \& Courtois, L. 2016. Novel 3D centimetre-to nano-scale quantification of an organic-rich mudstone: The Carboniferous Bowland Shale, Northern England. Marine and Petroleum Geology, 72, 193-205.

Macquaker, J.H.S. \& Adams, A.E. 2003. Maximizing information from fine-grained sedimentary rocks: an inclusive nomenclature for mudstones. Journal of Sedimentary Research, 73, 735-744.

Matlab. 2013. version 8.10.0 (R2013a). The MathWorks Inc.

Mavko, G., Mukerji, T. \& Dvorkin, J. 2009. The rock physics handbook : tools for seismic analysis of porous media. 2nd ed. Cambridge University Press, Cambridge.

Mckernan, R.E., Rutter, E.H., Mecklenburgh, J., Taylor, K.G. \& Covey-Crump, S.J. 2014. Influence of Effective Pressure on Mudstone Matrix Permeability: Implications for Shale Gas Production. SPE/EAGE European Unconventional Resources Conference and Exhibition. Society of Petroleum Engineers, Vienna, Austria, SPE-167762-MS.

Metwally, Y.M. \& Sondergeld, C.H. 2011. Measuring low permeabilities of gas-sands and shales using a pressure transmission technique. International Journal of Rock Mechanics and Mining Sciences, 48, 1135-1144.

Morrow, C.A., Lockner, D.A., Moore, D.E. \& Hickman, S. 2014. Deep permeability of the San Andreas fault from San Andreas fault observatory at depth (SAFOD) core samples. Journal of Structural Geology, 64, 99-114.

Morrow, C.A., Shi, L.Q. \& Byerlee, J.D. 1984. Permeability of fault gouge under confining pressure and shear stress. Journal of Geophysical Research: Solid Earth, 89, 31933200.

Nur, A. \& Byerlee, J.D. 1971. An exact effective stress law for elastic deformation of rock with fluids. Journal of Geophysical Research, 76, 6414-6419.

Pemberton, S.G. \& Gingras, M.K. 2005. Classification and characterizations of biogenically enhanced permeability. AAPG Bulletin, 89, 1493-1517.

Pye, K. \& Krinsley, D.H. 1986. Microfabric, mineralogy and early diagenetic history of the Whitby Mudstone Formation (Toarcian), Cleveland Basin, UK. Geological Magazine, 123, 191-203.

Randolph, P.L., Soeder, D.J. \& Chowdiah, P. 1984. Porosity and Permeability of Tight Sands. SPE Unconventional Gas Recovery Symposium, SPE-12836-MS, doi: 10.2118/12836-MS. 
Rawson, P.F. \& Wright, J.K. 1995. Jurassic of the Cleveland Basin, North Yorkshire. Field geology of the British Jurassic: Geological Society of London, 173-208.

Rutter, E.H., Hackston, A.J., Yeatman, E., Brodie, K.H., Mecklenburgh, J. \& May, S.E. 2013. Reduction of friction on geological faults by weak-phase smearing. Journal of Structural Geology, 51, 52-60.

Sayers, C.M. 2005. Seismic anisotropy of shales. Geophysical Prospecting, 53, 667-676, doi: 10.1111/j.1365-2478.2005.00495.x.

Schieber, J. 2011. Reverse engineering mother nature: Shale sedimentology from an experimental perspective. Sedimentary Geology, 238, 1-22.

Schieber, J., Southard, J.B. \& Schimmelmann, A. 2010. Lenticular shale fabrics resulting from intermittent erosion of water-rich muds - interpreting the rock record in the light of recent flume experiments. Journal of Sedimentary Research, 80, 119-128.

Schlömer, S. \& Krooss, B.M. 1997. Experimental characterisation of the hydrocarbon sealing efficiency of cap rocks. Marine and Petroleum Geology, 14, 565-580.

Schneider, C.A., Rasband, W.S. \& Eliceiri, K.W. 2012. NIH Image to ImageJ: 25 years of image analysis. Nature methods, 9, 671-675.

Seeburger, D.A. \& Nur, A. 1984. A pore space model for rock permeability and bulk modulus. Journal of Geophysical Research: Solid Earth, 89, 527-536.

Shi, J.-Q. \& Durucan, S. 2016. Near-exponential relationship between effective stress and permeability of porous rocks revealed in Gangi's phenomenological models and application to gas shales. International Journal of Coal Geology, 154-155, 111-122, doi: http://dx.doi.org/10.1016/j.coal.2015.12.014.

Song, I. \& Renner, J. 2007. Analysis of oscillatory fluid flow through rock samples. Geophysical Journal International, 170, 195-204, doi: 10.1111/j.1365246X.2007.03339.x.

Terzaghi, K. 1923. Thoretical Soil Mechanics. John Wiley, New York.

Turner, G.A. 1958. The flow-structure in packed beds: A theoretical investigation utilizing frequency response. Chemical Engineering Science, 7, 156-165, doi: http://dx.doi.org/10.1016/0009-2509(58)80022-6.

Walls, J. \& Nur, A. 1979. Pore pressure and confining pressure dependence of permeability in sandstone. Transactions of the 7th Formation Evaluation Symposium, 1-8.

Walsh, J.B. 1965a. The effect of cracks in rocks on Poisson's ratio. Journal of Geophysical Research, 70, 5249-5257.

Walsh, J.B. 1965b. The effect of cracks on the compressibility of rock. Journal of Geophysical Research, 70, 381-389.

Yang, Y. \& Aplin, A.C. 1998. Influence of lithology and compaction on the pore size distribution and modelled permeability of some mudstones from the Norwegian margin. Marine and Petroleum Geology, 15, 163-175.

Yang, Y. \& Aplin, A.C. 2007. Permeability and petrophysical properties of 30 natural mudstones. Journal of Geophysical Research: Solid Earth, 112, B03206, doi: 10.1029/2005JB004243.

Younglove, B.A. \& Hanley, H.J.M. 1986. The Viscosity and Thermal Conductivity Coefficients of Gaseous and Liquid Argon. Journal of Physical and Chemical Reference Data, 15, 1323-1337, doi: doi:http://dx.doi.org/10.1063/1.555765.

Zhang, T., Ellis, G.S., Ruppel, S.C., Milliken, K. \& Yang, R. 2012. Effect of organic-matter type and thermal maturity on methane adsorption in shale-gas systems. Organic Geochemistry, 47, 120-131, doi: http://dx.doi.org/10.1016/j.orggeochem.2012.03.012.

Zimmerman, R.W., Somerton, W.H. \& King, M.S. 1986. Compressibility of porous rocks. Journal of Geophysical Research: Solid Earth, 91, 12765-12777, doi: 10.1029/JB091iB12p12765. 
Zoback, M.D. \& Byerlee, J.D. 1975. Permeability and effective stress: Geologic notes. AAPG Bulletin, 59, 154-158. 


\section{Tables}

Table 1. Sample dimensions and porosity.

\begin{tabular}{llll}
\hline Sample & Length $(\mathrm{m})$ & Diameter $(\mathrm{m})$ & Porosity \\
\hline RA1 & 0.01919 & 0.02439 & 0.086 \\
RA2 & 0.03133 & 0.02436 & 0.087 \\
RA6 & 0.03127 & 0.02463 & 0.081 \\
RA12 & 0.02723 & 0.02451 & 0.072 \\
RA13 & 0.02723 & 0.02435 & \\
RA14 & 0.02521 & 0.02449 & 0.073 \\
& & & \\
& & & \\
RC7 & 0.01694 & 0.02455 & 0.087 \\
\hline
\end{tabular}

Table 2. Results from empirical fits to equation 18 with errors for fit parameters and overall RMS error of the fit. The samples with no value for $\chi$ were tested at a constant pore pressure of $25 \mathrm{MPa}$. In the remaining tests the pore pressure and confining pressure were both varied.

\begin{tabular}{|c|c|c|c|c|c|c|c|}
\hline Sample & $\begin{array}{l}k_{0} \times 10^{-21} \\
\left(\mathrm{~m}^{2}\right)\end{array}$ & $\begin{array}{l}\delta k_{0} \times 10^{-21} \\
\left(\mathrm{~m}^{2}\right)\end{array}$ & $\begin{array}{l}\gamma \\
\left(\mathrm{MPa}^{-1}\right)\end{array}$ & $\delta \gamma\left(\mathrm{MPa}^{-1}\right)$ & $\chi$ & $\delta \chi$ & $\begin{array}{l}\text { RMS error } \\
\log \left(k \mathrm{~m}^{2}\right)\end{array}$ \\
\hline RA1 & 179 & 38 & -0.031 & 0.005 & & & 0.199 \\
\hline RA2 & 180 & 32 & -0.026 & 0.003 & 0.601 & 0.228 & 0.116 \\
\hline RA6 & 90.5 & 14.0 & -0.037 & 0.004 & & & 0.168 \\
\hline RA12 & 26.4 & 3.8 & -0.009 & 0.002 & 0.564 & 0.244 & 0.058 \\
\hline RA13 & 7.81 & 1.80 & -0.021 & 0.004 & 0.973 & 0.322 & 0.107 \\
\hline RA14 & 7.86 & 0.96 & -0.022 & 0.003 & & & 0.120 \\
\hline $\begin{array}{l}\text { RA14 } \\
\text { cycle } 1\end{array}$ & 34.3 & 7.2 & -0.030 & 0.004 & 0.964 & 0.194 & 0.039 \\
\hline $\begin{array}{l}\text { RA14 } \\
\text { cycle } 2\end{array}$ & 11.0 & 1.3 & -0.021 & 0.002 & 0.756 & 0.109 & 0.042 \\
\hline $\begin{array}{l}\text { RA14 } \\
\text { cycle } 3\end{array}$ & 8.41 & 0.97 & -0.021 & 0.002 & 0.422 & 0.097 & 0.064 \\
\hline RC7 & 2.39 & 0.28 & -0.023 & 0.002 & & & 0.075 \\
\hline
\end{tabular}


Table 3. Compressional wave velocity parallel to layering $\left(V_{11}\right)$ and perpendicular to layering $\left(V_{33}\right)$ and calculated components of Voigt stiffness matrix $\left(C_{i j}\right)$ assuming transverse isotropy with symmetry axis $\left(x_{3}\right)$ perpendicular to layering.

\begin{tabular}{lllll}
\hline Cycle & $V_{11}\left(\mathrm{~ms}^{-1}\right)$ & $V_{33}\left(\mathrm{~ms}^{-1}\right)$ & $C_{11}(\mathrm{GPa})$ & $C_{33}(\mathrm{GPa})$ \\
\hline 1 & 4527.00 & 3498.00 & 51.23 & 30.59 \\
2 & 4531.00 & 3525.00 & 51.32 & 31.06 \\
3 & & 3468.00 & & 30.07 \\
\hline
\end{tabular}

Table 4. Calculated matrix isotropic elastic properties. A Voigt-Reuss-Hill (VRH) average of the solid phases assuming no lattice preferred orientation and phase proportions measured from SEM and XRD and elastic properties of individual phases taken from literature. Porosity is included using self-consistent (SC) approach of Berryman (1995) following routines from Mavko et al. (2009) with VRH average of the solid phases as the matrix properties. $V_{p}$ is compressional wave velocity, $C_{11}$ is a component of the stiffness matrix, $K$ is bulk modulus, $\mu$ is shear modulus, $v$ is Poisson's ratio and $\alpha$ is the aspect ratio of pores. The emboldened values are those used for the elastic properties of the matrix in the pore network model.

\begin{tabular}{lllllll}
\hline & $V_{\mathrm{p}}\left(\mathrm{ms}_{-1}\right)$ & $C_{11}(\mathrm{GPa})$ & $K(\mathrm{GPa})$ & $\mu(\mathrm{GPa})$ & $v$ & $\alpha$ \\
\hline VRH solids & 6041.04 & 91.24 & 51.47 & 29.83 & 0.26 & \\
SC 6\% spherical porosity & 5641.77 & 79.57 & 44.50 & 26.31 & 0.25 & \\
SC 6\% elliptical porosity & 4213.17 & 44.38 & 21.53 & 17.13 & 0.19 & 0.05 \\
& $\mathbf{4 6 1 1 . 7 6}$ & $\mathbf{5 3 . 1 7}$ & $\mathbf{2 6 . 7 4}$ & $\mathbf{1 9 . 8 3}$ & $\mathbf{0 . 2 0}$ & $\mathbf{0 . 0 7}$ \\
& 4745.14 & 56.29 & 28.67 & 20.72 & 0.21 & 0.08 \\
& 4852.28 & 58.86 & 30.30 & 21.42 & 0.21 & 0.09 \\
& 4940.30 & 61.02 & 31.69 & 22.00 & 0.22 & 0.10 \\
& 5361.23 & 71.86 & 39.00 & 24.64 & 0.24 & 0.20 \\
& 5604.16 & 78.52 & 43.74 & 26.08 & 0.25 & 0.50 \\
& 5636.38 & 79.42 & 44.39 & 26.27 & 0.25 & 0.75 \\
\hline
\end{tabular}


Table 5. Results from the seismic velocity model and pore transport model, sample RA14.

\begin{tabular}{l|llll|ll}
\hline & \multicolumn{3}{|l|}{ Seismic Velocity Model } & & Pore Transport Model \\
\hline Cycle & $\begin{array}{l}\text { Pressure } \\
\text { Range }\end{array}$ & $\begin{array}{l}\text { Crack } \\
\text { Porosity } \\
\phi_{\text {crack }}\end{array}$ & $\begin{array}{l}\text { Average } \\
\text { Aspect } \\
\text { Ratio } \hat{\alpha}\end{array}$ & $\begin{array}{l}\text { Standard } \\
\text { Deviation of } \\
\text { Aspect Ratio } \sigma_{\alpha}\end{array}$ & $\begin{array}{l}\text { Transport } \\
\text { Porosity }\end{array}$ & $\begin{array}{l}\text { Pore } \\
\text { widths } b_{0} \\
(\mathrm{~nm})\end{array}$ \\
\hline 1 & $0-20$ & 0.0039 & 0.00266 & 0.9576 & 0.07 & 3.7 \\
1 & $10-100$ & 0.0086 & 0.00675 & 0.9576 & 0.025 & 2.2 \\
2 & $10-100$ & 0.0086 & 0.00759 & 0.9576 & 0.022 & 1.8 \\
3 & $10-100$ & 0.0089 & 0.00763 & 0.9576 & 0.022 & 1.8 \\
\hline
\end{tabular}




\section{Appendix}

Based on scattering theory, Hudson $(1980,1981)$ set out how the effective moduli for a medium with ellipsoidal cracks can be calculated (see Mavko et al. 2009 page 194). This formulation has the problem that at high crack densities the equations predict that elastic moduli will increase with increasing crack density. This problem was corrected by Cheng (1993) using a different formulation. Cheng (1993) showed that the effective elastic stiffness $C_{i j}^{*}$ can be calculated more precisely using:

$$
C_{i j}^{*}=C_{i j}^{0} \frac{1-a_{i j} \Gamma}{1+b_{i j} \Gamma}
$$

where $C_{i j}^{0}$ is the 6 x 6 Voigt elastic stiffness matrix, $\Gamma$ is the crack density and $a_{i j}$ and $b_{i j}$ are given by:

$$
a_{i j}=-\frac{C_{i j}^{1}}{C_{i j}^{0} \Gamma}-b_{i j} ; \quad b_{i j}=-\frac{C_{i j}^{2}}{C_{i j}^{1} \Gamma} .
$$

For a parallel array of oblate, thin cracks with their crack normals all parallel to $x_{3}$ the resulting aggregate will be transversely isotropic with its symmetry axis also parallel to $x_{3}$ (Note superscripts in equation A2 are not powers but are the first- and second-order terms). The $C_{i j}^{1}$ and $C_{i j}^{2}$ important for a transversely isotropic rock are:

$$
\begin{array}{cc}
\text { First-order terms } & \text { Second-order terms } \\
C_{11}^{1}=-\frac{\lambda^{2}}{\mu} \Gamma U_{3} & C_{11}^{2}=\frac{q}{15} \frac{\lambda^{2}}{(\lambda+2 \mu)}\left(\Gamma U_{3}\right)^{2} \\
C_{13}^{1}=-\frac{\lambda(\lambda+2 \mu)}{\mu} \Gamma U_{3} & C_{13}^{2}=\frac{q}{15} \lambda\left(\Gamma U_{3}\right)^{2} \\
C_{33}^{1}=-\frac{(\lambda+2 \mu)^{2}}{\mu} \Gamma U_{3} & C_{33}^{2}=\frac{q}{15}(\lambda+2 \mu)\left(\Gamma U_{3}\right)^{2} \\
C_{44}^{1}=-\mu \Gamma U_{1} & C_{33}^{2}=\frac{2}{15} \frac{\mu(3 \lambda+8 \mu)}{\lambda+2 \mu}\left(\Gamma U_{3}\right)^{2} \\
C_{66}^{1}=0 & C_{66}^{2}=0
\end{array}
$$

where

$$
\begin{gathered}
q=15 \frac{\lambda^{2}}{\mu^{2}}+28 \frac{\lambda}{\mu}+28 \\
\Gamma=\frac{N}{V} a^{3}=\frac{3 \phi}{4 \pi \alpha}
\end{gathered}
$$

and for weak inclusions 


$$
U_{1}=\frac{16(\lambda+2 \mu)}{3(2 \lambda+4 \mu)} \frac{1}{(1+M)} \quad U_{3}=\frac{4(\lambda+2 \mu)}{3(\lambda+\mu)} \frac{1}{(1+\kappa)}
$$

where

$$
M=\frac{4 \mu^{\prime}}{\pi \alpha \mu} \frac{(\lambda+2 \mu)}{(3 \lambda+4 \mu)} \quad \kappa=\frac{\left(K^{\prime}+\frac{4}{3} \mu^{\prime}\right)}{\pi \alpha \mu} \frac{(\lambda+2 \mu)}{(\lambda+\mu)}
$$

where $K$ and $K$ ' are the bulk moduli of matrix and the weak phase or fluid in the cracks respectively and $\mu$ and $\mu^{\prime}$ are the shear modulus of the matrix and the weak phase or fluid respectively. As there is gas in the pores the values of $M=0$ and $\kappa$ will be very close to zero as $\mu^{\prime}=0$ and $K^{\prime} \ll K$ so the equations for $U_{1}$ and $U_{3}$ simplify to the dry case.

$$
U_{1}=\frac{16(\lambda+2 \mu)}{3(2 \lambda+4 \mu)} \quad U_{3}=\frac{4(\lambda+2 \mu)}{3(\lambda+\mu)}
$$

Because the compressional wave velocity is measured parallel to the layering $V_{\mathrm{P}}\left(90^{\circ}\right)$ i.e. parallel to $x_{1}$ direction and the compressional wave velocity perpendicular to the layering $V_{\mathrm{P}}\left(0^{\circ}\right)$ i.e. parallel to $x_{3}$, two components of the full transversely anisotropic elasticity matrix, $C_{11}$ and $C_{33}$ can be calculated:

$$
C_{11}=\rho V_{P}^{2}\left(90^{\circ}\right) \quad C_{33}=\rho V_{P}^{2}\left(0^{\circ}\right)
$$

The equations above can be used to invert for the crack density assuming a bulk modulus and shear modulus of the isotropic matrix. Because $C_{33}$ has a stronger dependence on crack density than $C_{11}$ it tends to dominate the inversion for crack density. The accuracy of the crack density determined is unaffected by only using $V_{33}$ to invert for crack density. If five independent velocity measurement are made $V_{\mathrm{P}}\left(0^{\circ}\right), V_{\mathrm{P}}\left(90^{\circ}\right), V_{\mathrm{P}}\left(45^{\circ}\right), V_{\mathrm{SH}}\left(0^{\circ}\right)$ and $V_{\mathrm{SH}}\left(90^{\circ}\right)$ the full transversely isotropic elasticity tensor can be determined and it should be potentially be possible to invert for both crack density and average crack aspect ratio. 


\section{Figures}

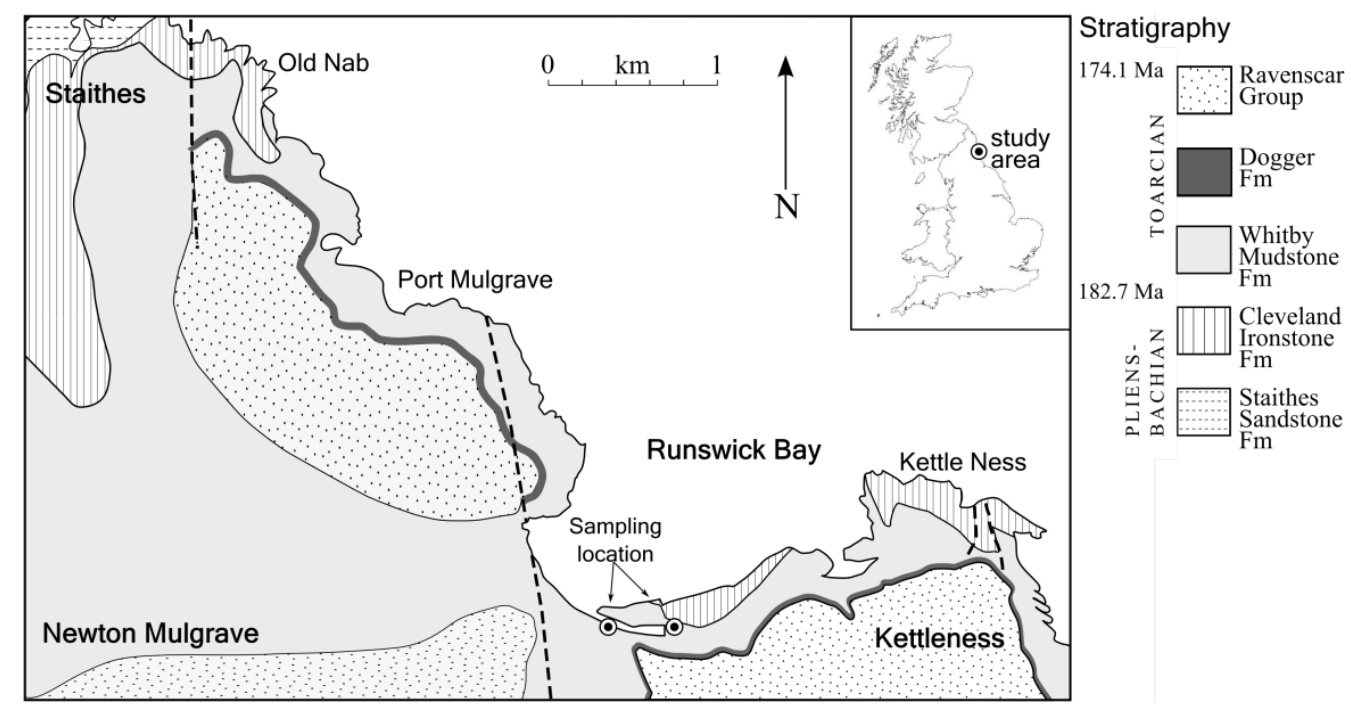

Figure 1. Geological map showing the sampling locations at Runswick bay, North Yorkshire. 

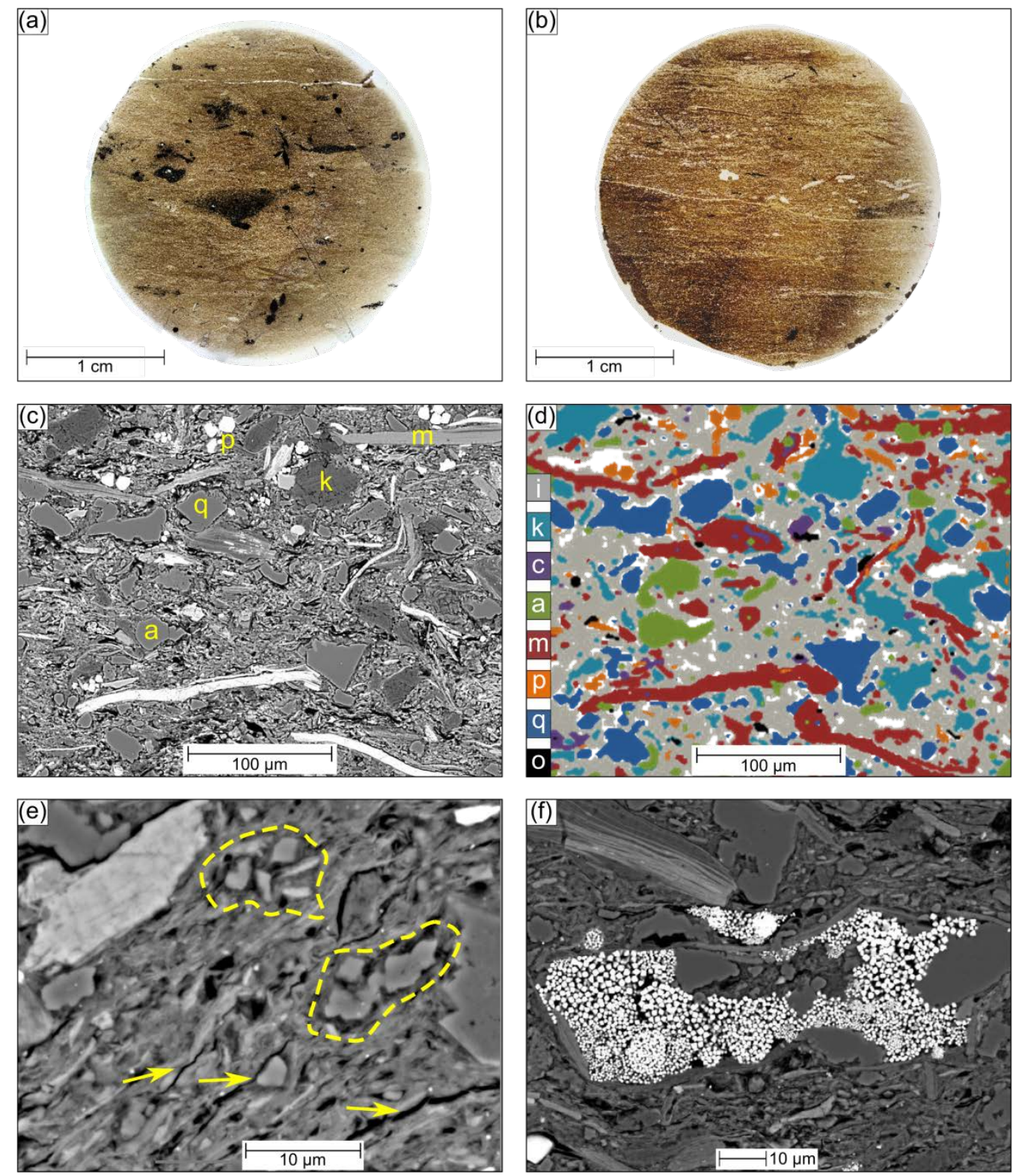

Figure 2. Photomicrographs showing the composition and texture of the Whitby Mudstone.

(a) Thin-section image normal to bedding showing sample RA2. Burrows are in-filled with diagenetic pyrite (black). (b) Thin-section image normal to bedding showing sample RA13. Small burrows infilled with either clay or quartz silt are set in a bioturbated, clay-dominated host sediment. Diagenetic pyrite is absent. (c) Scanning electron photomicrograph showing silt grains comprising quartz (q), albite (a), muscovite/chlorite (m) set in a matrix dominated by illite (i) and kaolinite (k) with minor amorphous organic matter and pyrite (p). (d) Mineral map of the area in (a). c is carbonate and (o) is organic matter. (e) Scanning electron photomicrograph showing preferred orientation of clay matrix and of microcracks (arrows) and porosity protected from compaction by clusters of silt grains (circled yellow). (f) Scanning electron photomicrograph showing porosity within euhedral pyrite aggregates. 


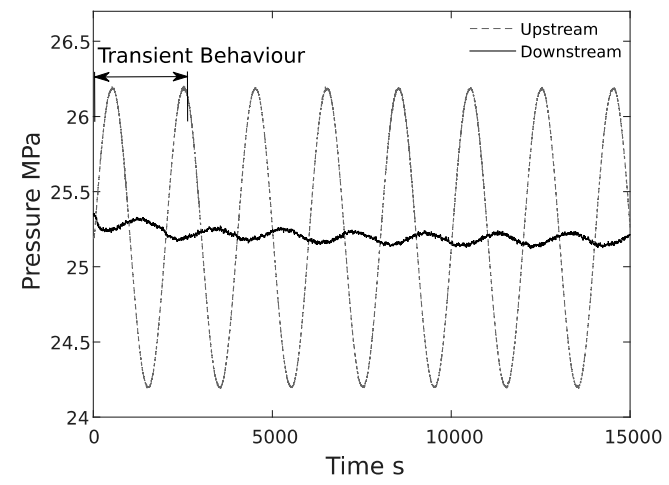

Figure 3. Example of upstream and downstream signals for experiment RA14 at confining pressure 75 MPa and pore pressure 25 MPa. Period of the upstream wave is $2000 \mathrm{~s}$ and the amplitude $1 \mathrm{MPa}$. The downstream pore pressure typically exhibits transient behaviour before settling to steady state.

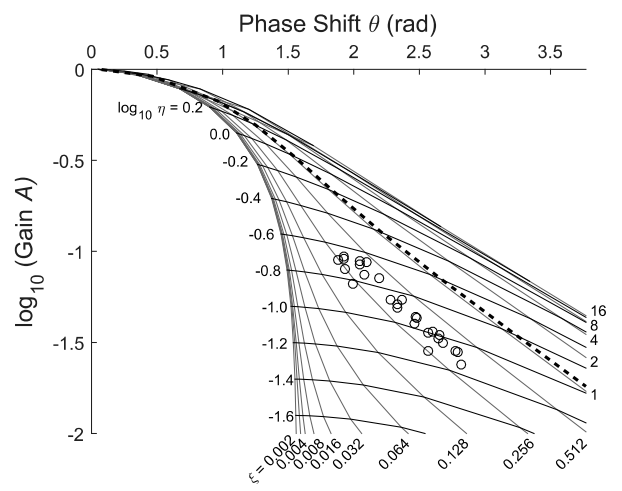

Figure 4. Solution space showing the region in which physically meaningful values of $A$ and $\theta$ can be found, delimited by the iso- $\xi$ lines $\xi=0$ and $\xi \rightarrow \infty$. Storativity ratio $(\xi)$ is proportional to porosity, thus iso- $\xi$ paths are approximately lines of constant porosity. Permeability data for sample RA14 is plotted as open circles. As permeability (proportional to $\eta$ ) decreases with increasing confining pressure, the data points migrate downwards roughly following the same iso- $\xi$ path. The dashed line indicates the dimensionless storativity ratio $\xi$ calculated using equation 6 when storativity $(\beta)$ is calculated from the measured helium porosity using equation 8. 


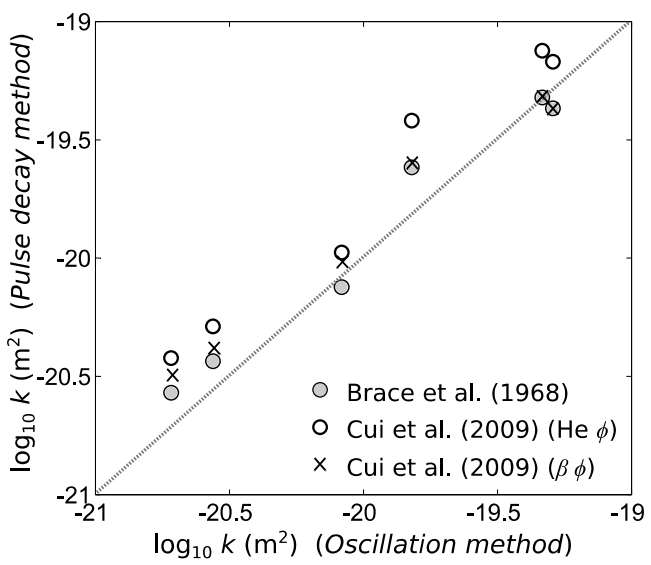

Figure 5. Comparison of permeabilities measured using the oscillating pore pressure method (Bernabé et al. 2006), with the transient pulse decay method (Brace et al. 1968) applied immediately afterwards. Transient pulse decay measurements were processed using both equation 12 (Brace et al. 1968) (grey circles) and equation 15 (Cui et al. 2009) which takes porosity into account. When using equation 15, porosity was set as either derived from helium pyncnometry (He $\phi$ ) (open circles) or porosity calculated from equation 8 when storativity $\beta$ is calculated from equation 6 using the dimensionless storativity ratio $\xi$ determined from the pore pressure oscillation measurement (black crosses).

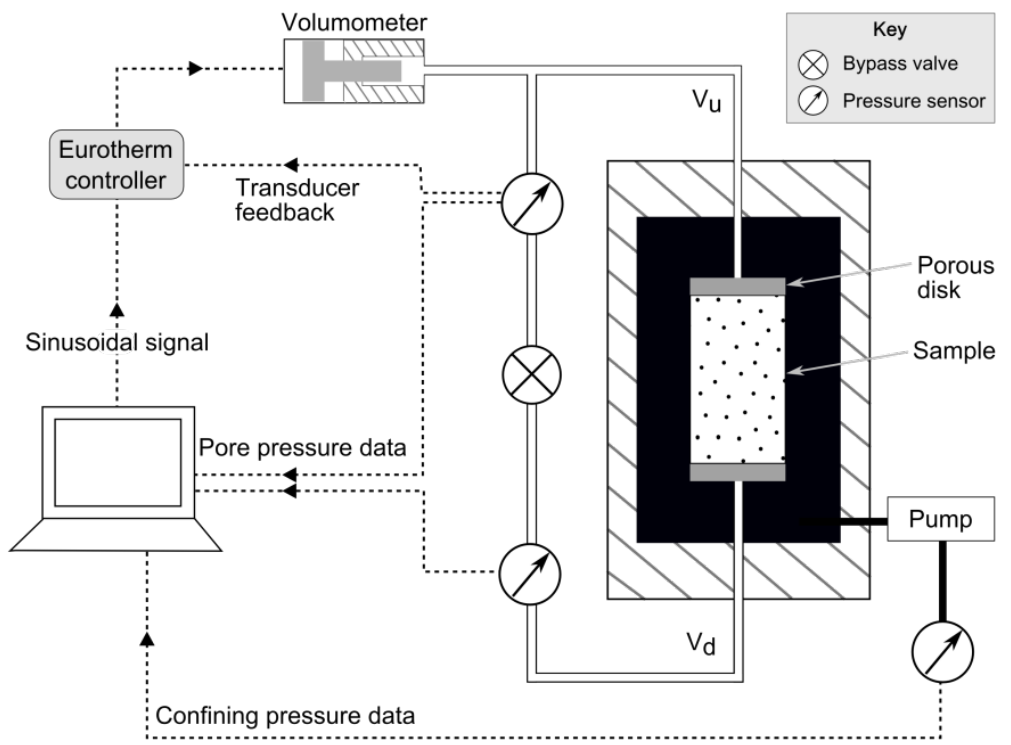

Figure 6. Schematic diagram of experimental setup used for permeability experiments. 

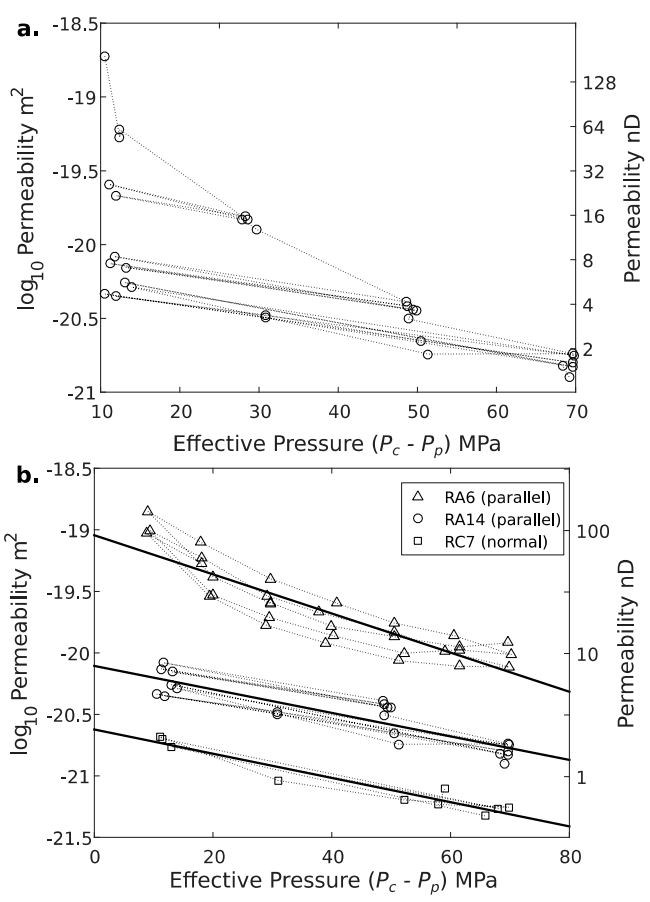

Figure 7. a. Permeability plotted as a function of effective pressure at a constant pore pressure showing the evolution of during pressure cycling. b. Permeability plotted as a function of effective pressure at a constant pore pressure of $25 \mathrm{MPa}$ for two bedding-parallel and one bedding-normal core plugs of Whitby Mudstone, after an initial application of effective pressure up to $70 \mathrm{MPa}$, during which a permanent decrease of almost 2 orders of magnitude occurred. Measurement uncertainty is less than symbol size. Fitted lines describe exponential decrease of permeability with effective pressure.

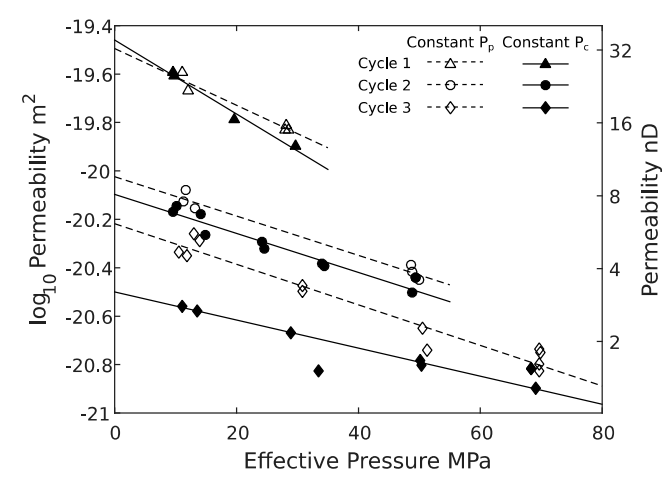

Figure 8. Permeability as a function of effective pressure measured at both constant pore pressure (dashed line and open symbols) and constant confining pressure (solid line and closed symbols) across three different pressure ranges in sample RA14 cored parallel to bedding. Permeability decreases permanently with each increment of pressure (labelled 
cycle 1, cycle 2, cycle 3), resulting in a cumulative permeability decrease of almost 2 orders of magnitude over the full $70 \mathrm{MPa}$ pressure range. This is followed by reproducible elastic behaviour for pressure cycles up to the previously highest pressure attained. Slopes for constant pore pressure and constant confining pressure data are approximately the same.
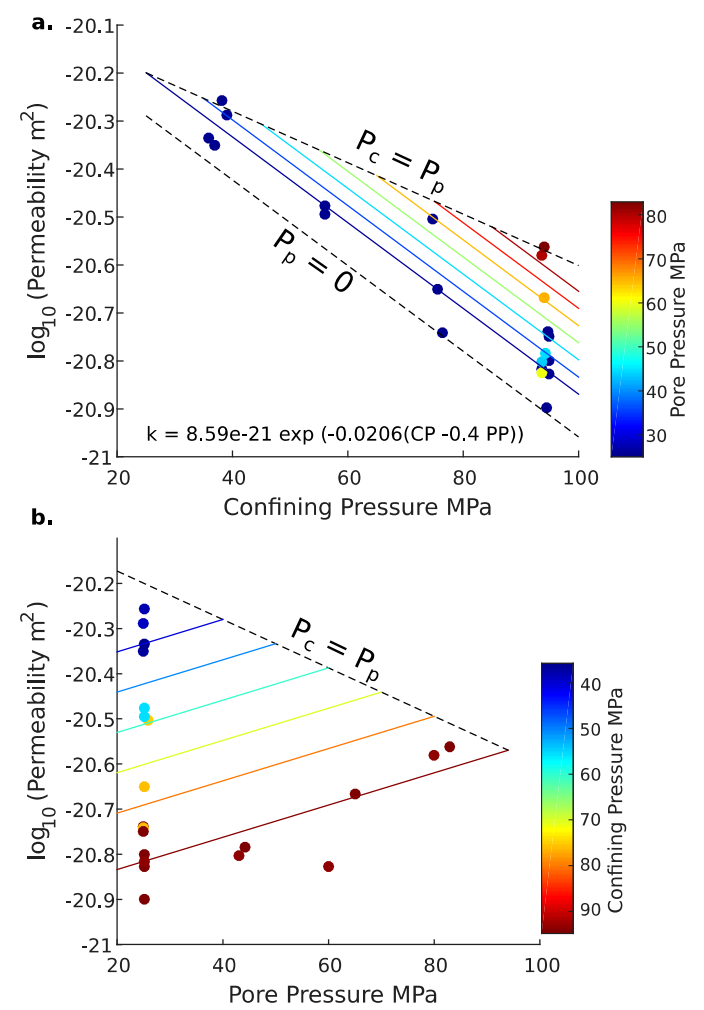

Figure 9. Comparison of permeability data for sample RA14 (coloured circles) with permeability predicted using equation 18 (coloured lines). $\boldsymbol{a}$ and $\boldsymbol{b}$ respectively use total confining pressure and pore pressure for the pressure axis. When the bounding line $P_{p}=P_{c}$ has a positive slope $\chi>1$; when the slope is zero, $\chi=1$, and when the slope is negative, $\chi<1$. 


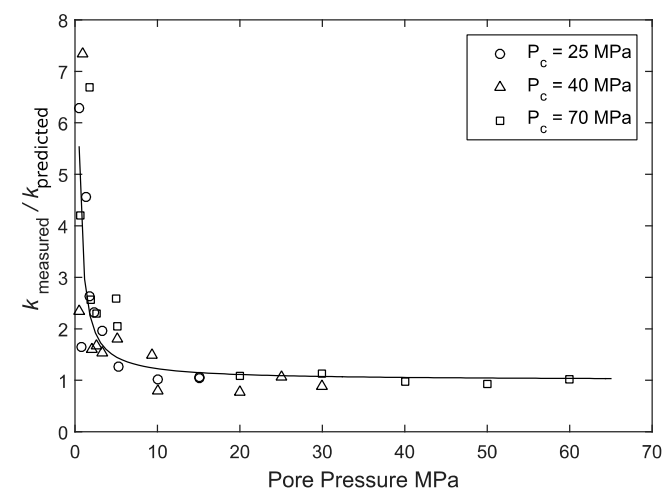

Figure 10. Measured permeability data normalised to that predicted by best fit to high pore pressure data $\left(k_{\text {measured }} / k_{\text {predicted }}\right)$ where $k_{\text {predicted }}$ is given by equation 19 plotted against pore pressure. The plot illustrates the magnitude of deviations from the original permeability trend and shows that the upper pore pressure limit for gas slippage effects is $10 \mathrm{MPa}$. This is described by a Klinkenberg parameter $K_{b}$ (equation 4) of $2 \mathrm{MPa}$. The continuous fitted curve is equation 19.
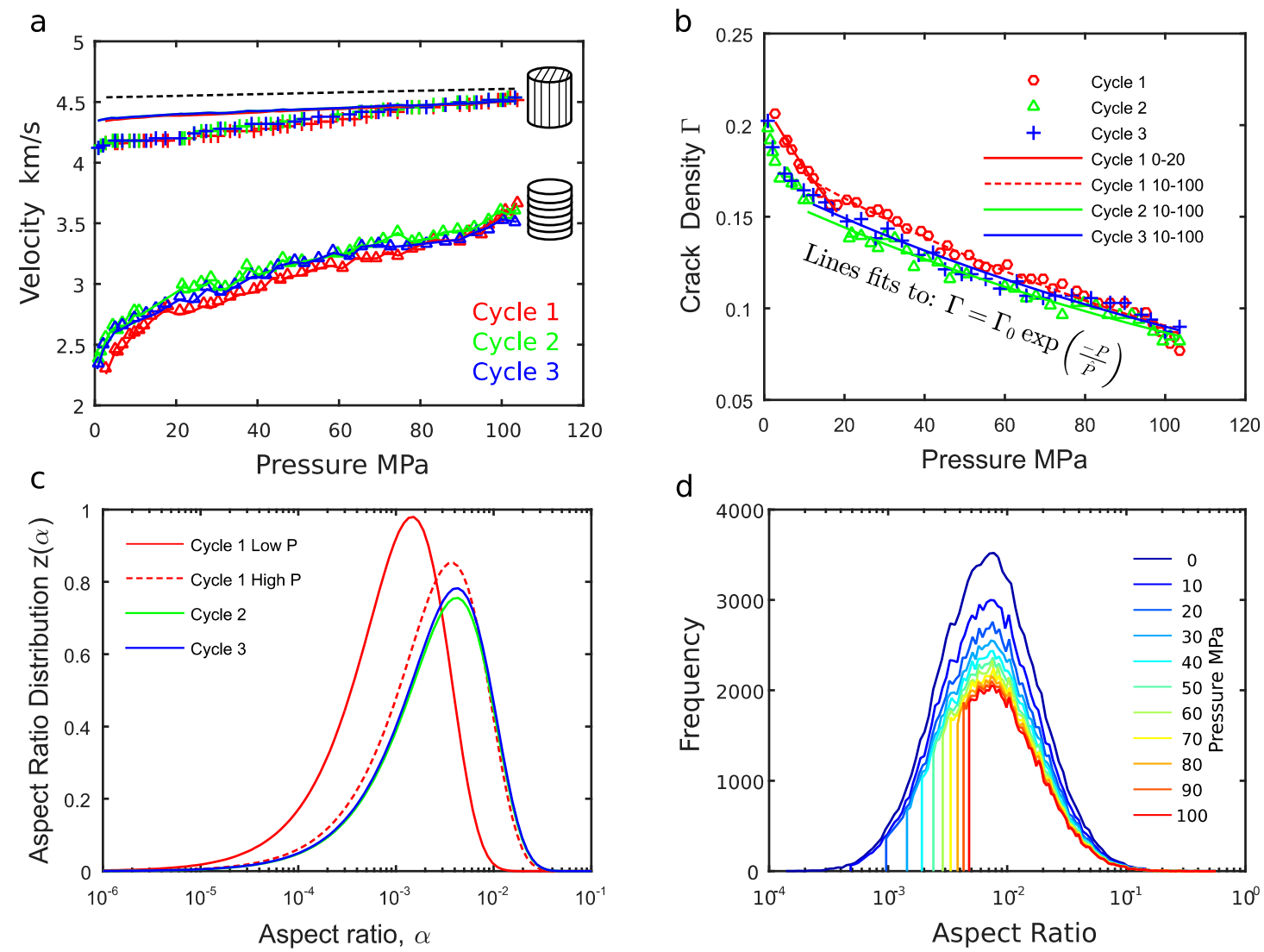

Figure 11. (a) Ultrasonic compressional wave velocity measurements on Whitby Mudstone for core samples oriented with axes both parallel normal to layering for three pressure cycles 
(only up-pressure part of each cycle shown). For wave propagation normal to layering velocities increase between each cycle during loading paths. Solid lines are fits to velocities calculated from crack densities obtained using the approach of (Cheng 1993). Correspondence is good for the layering-normal orientation but there is deviation at lower pressures for the layering-parallel orientation. Black dashed line is theoretical velocity of a crack free isotropic rock. (b) Crack densities versus pressure calculated from velocity data for successive pressure cycles using the approach of (Cheng 1993) and detailed in appendix. Data are fitted to equation 25 (solid lines) over the pressure ranges (in MPa) shown in legend. (c) Aspect ratio distribution of cracks closing with applied effective pressure, determined using equation 30. Modal aspect ratios are shown in Table 5 together with the standard deviations calculated assuming distributions can be approximated as log-normal. (d) Zero pressure log-normal distributions of aspect ratio generated using a pseudo random number generator for use in the pore conductivity model (equation 30). The aspect ratio distribution is based on values obtained from change in crack density with pressure. The lowest aspect ratio cracks close as pressure is increased and are removed from the pore conductivity model causing the cut off of low aspect ratios at higher pressures.
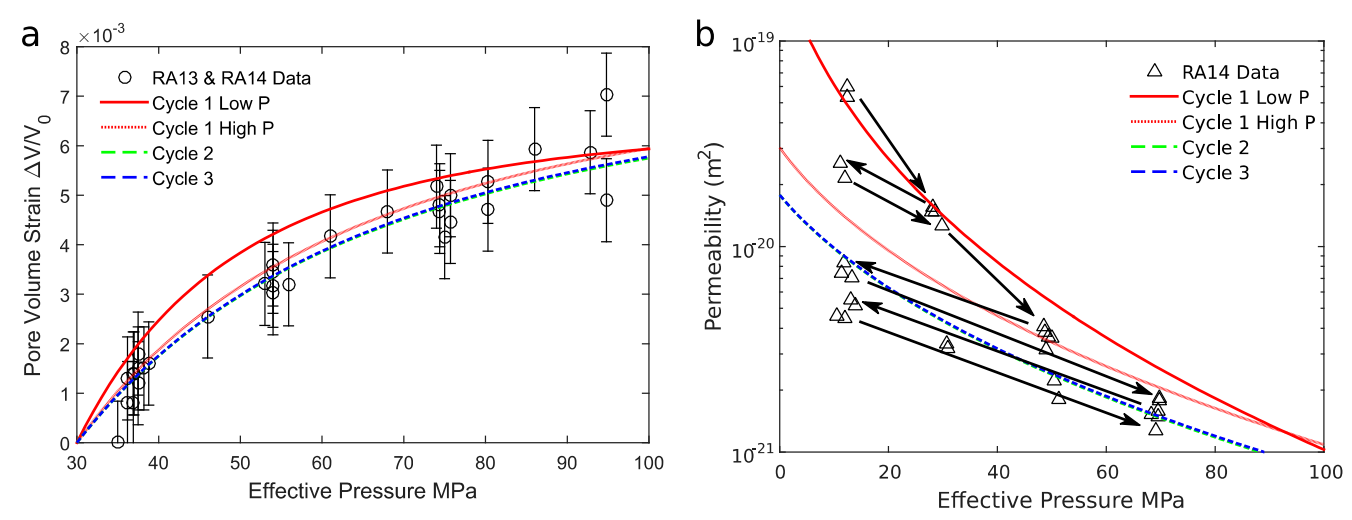

Figure 12. (a) Pore volume strain versus effective pressure experimental data for samples RA13 and RA14 (combined) of Whitby Mudstone. Lines show predicted curves of total pore volume strain when most of the porosity is hosted within isolated, spherical pores and the remainder of the porosity is hosted within elliptical pores with the log-normal aspect ratio distribution of the conductive crack network (Figure 11d). The different cycles and the low pressure and high pressure curves for cycle 1 refer to the different aspect ratio distributions (Figure 11c) calculated from how crack density changes with pressure (Figure 11b). The fit was optimised by varying the proportions of conductive porosity to total porosity. The 
stiffness of the rock increases with pressure as cracks are progressively closed (fits are upward-convex), although the general linear trend of the experimental data corresponds to a bulk compressibility of approximately $8 \mathrm{GPa}$. (b) Permeability calculated as a function of effective pressure using equation 36. Data are for sample RA14 (this is the same data as shown in Figure 8 and also the later cycles are shown in Figure 7). Fit parameters are given in Table 5. The aspect ratio distribution calculated for pressures below 20 MPa for cycle 1 (Figures $11 \mathrm{c}$ and 11d) fits well with the permeability data for initial pressurization. The permeability calculated from the aspect ratio distributions calculated for the later cycles also fit well with data for the later cycles of pressurization.

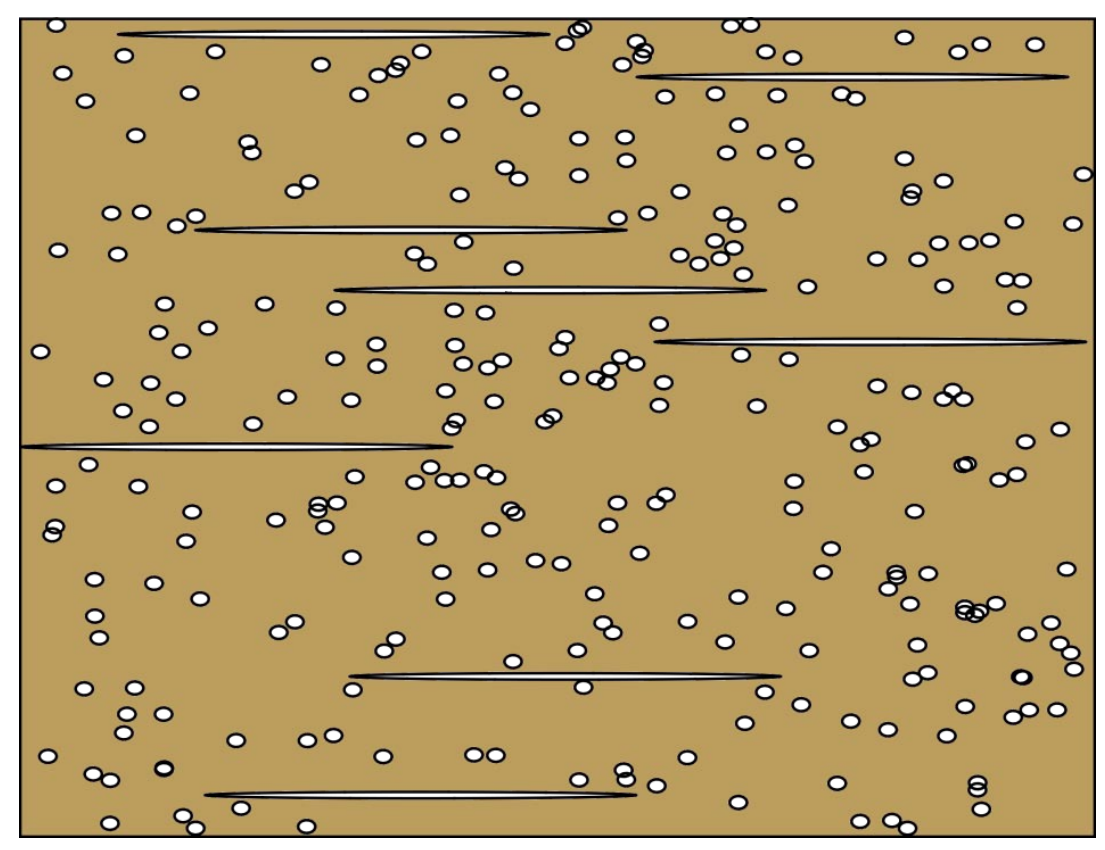

Figure 13. Schematic illustration of the structure of the pore network in the Whitby Mudstone inferred from measurements of velocity, bulk compressibility and permeability. Higher aspect ratio pores ( $\alpha=0.75$ ) constitute most of the pore volume $(\phi=0.06)$, but act mostly as storage pores. High aspect ratio cracks $(\alpha=0.015$ and $\phi=0.02)$ form an out-of-plane connected, fluid-conducting network which progressively closes down with increasing pressure, reducing permeability. 